\title{
The antiproliferative and proapoptotic effects of cladosporols A and B are related to their different binding mode as PPAR $\gamma$ ligands
}

\author{
Diana Zurlo ${ }^{\mathrm{a}, 1}$, Pamela Ziccardi ${ }^{\mathrm{a}, 1}$, Carolina Votino ${ }^{\mathrm{a}}$, Tommaso Colangelo ${ }^{\mathrm{a}}$, Carmen Cerchia ${ }^{\mathrm{b}}$, \\ Fabrizio Dal Piaz ${ }^{c}$, Sabrina Dallavalle ${ }^{\mathrm{d}}$, Salvatore Moricca ${ }^{\mathrm{e}}$, Ettore Novellino ${ }^{\mathrm{b}}$, Antonio Lavecchia ${ }^{\mathrm{b}, *}$, \\ Vittorio Colantuoni ${ }^{a}$, Angelo Lupo ${ }^{\mathrm{a}, *}$ \\ ${ }^{a}$ Dipartimento di Scienze e Tecnologie, Università del Sannio, via Port'Arsa 11, 82100 Benevento, Italy \\ b Dipartimento di Farmacia, “Drug Discovery" Laboratory, Università degli Studi di Napoli Federico II, via D. Montesano 49, 80131 Napoli, Italy \\ ' Dipartimento di Farmacia, Università degli Studi di Salerno, via Giovanni Paolo II, 132, 84084 Fisciano, Italy \\ ${ }^{\mathrm{d}}$ Dipartimento di Scienze per gli Alimenti, la Nutrizione e l'Ambiente, Università degli Studi di Milano, via Celoria 2, 20133 Milano, Italy \\ e Dipartimento di Scienze delle Produzioni Agroalimentari e dell'Ambiente (DiSPAA), Università degli Studi di Firenze, Piazzale delle Cascine 18, 50144 Firenze, Italy
}

\section{A R T I C L E I N F O}

\section{Article history:}

Received 4 December 2015

Accepted 11 March 2016

Available online 17 March 2016

\section{Keywords:}

Cladosporols

Apoptosis

Colorectal cancer cells

Full and partial PPAR $\gamma$ agonists

Docking

\begin{abstract}
A B S T R A C T
Cladosporols are secondary metabolites from Cladosporium tenuissimum characterized for their ability to control cell proliferation. We previously showed that cladosporol A inhibits proliferation of human colon cancer cells through a PPAR $\gamma$-mediated modulation of gene expression. In this work, we investigated cladosporol B, an oxidate form of cladosporol A, and demonstrate that it is more efficient in inhibiting HT-29 cell proliferation due to a robust G0/G1-phase arrest and p21 waf1/cip1 overexpression. Cladosporol B acts as a PPAR $\gamma$ partial agonist with lower affinity and reduced transactivation potential in transient transfections as compared to the full agonists cladosporol A and rosiglitazone. Site-specific PPAR $\gamma$ mutants and surface plasmon resonance (SPR) experiments confirm these conclusions. Cladosporol B in addition displays a sustained proapoptotic activity also validated by $\mathrm{p} 21^{\text {waf } 1 / \mathrm{cip} 1}$ expression analysis in the presence of the selective PPAR $\gamma$ inhibitor GW9662. In the DMSO $/ \mathrm{H}_{2} \mathrm{O}$ system, cladosporols A and B are unstable and convert to the ring-opened compounds $\mathbf{2 A}$ and $\mathbf{2 B}$. Finally, docking experiments provide the structural basis for full and partial PPAR $\gamma$ agonism of 2A and 2B, respectively. In summary, we report here, for the first time, the structural characteristics of the binding of cladosporols, two natural molecules, to PPAR $\gamma$. The binding of compound 2B is endowed with a lower transactivation potential, higher antiproliferative and proapoptotic activity than the two full agonists as compound $\mathbf{2 A}$ and rosiglitazone (RGZ).
\end{abstract}

(C) 2016 Elsevier Inc. All rights reserved.

\section{Introduction}

Natural molecules isolated and characterized from plants, fungi and microorganisms represent a source of new drugs for cancer

Abbreviations: CAD, caspase-activated deoxyribonuclease; CRC, colorectal cancer; HR-ESI-MS, high resolution electrospray ionization mass; LBD, ligandbinding domain; MDA, malondialdehyde; NCoEx, nuclear corepressor exchange factor; PPARs, peroxisome proliferator-activated receptors; PBS, phosphate saline buffer; PPAR $\gamma$, peroxisome proliferator-activated receptor $\gamma$; PPRE, PPAR response element; POX/PRODH, proline oxidase/proline dehydrogenase; RGZ, rosiglitazone; RSV, Rous Sarcoma Virus; RXR, retinoid X receptor; ROS, reactive oxygen species; SPPARMs, Selective PPAR $\gamma$ Modulators; SPR, surface plasmon resonance; TCF, T-cell factor; TMS, tetramethylsilane; TZDs, thiazolinediones.

* Corresponding authors.

E-mail addresses: antonio.lavecchia@unina.it (A. Lavecchia), lupo@unisannio.it (A. Lupo).

1 These authors equally contributed to the work treatment. Their employment is advantageous because they generally are less expensive and act as multitargeted therapeutics, a feature that is absolutely beneficial to the treatment of solid tumors caused by dysregulation of several genes. Natural compounds usually have lower affinity and thus lower toxicity than synthetic drugs so that they do not interfere with most of the essential biological functions.

Among natural compounds, carotenoids, flavonoids, organosulfurs, isothiocyanates, indoles and monoterpenes have been associated with a reduced risk of cancer in a large series of epidemiological and preclinical studies [1-3]. In addition, they are very useful in the management of cancer patients either alone or in combination with known molecules [4-6].

In the search for novel natural molecules, we recently demonstrated that cladosporol A, a secondary metabolite from Cladosporium tenuissimum, exhibits antiproliferative properties in a variety 
of human colon cancer cell lines through modulation of several cell cycle gatekeeper gene expression (p21 waf1/cip1, cyclin D1, cyclin E, CDK2, CDK4) [7]. These effects are mediated by PPAR $\gamma$ to which Cladosporol $A$ binds as a ligand, activating, in turn, p2 $1^{\text {waf1/cip1 }}$ gene expression in an Sp1-dependent manner [8]. Cladosporol A-bound PPAR $\gamma$ targets $\beta$-catenin to proteasomal degradation, reducing the overall amount of the protein and transcription of its target genes [8]. In addition, it stimulates E-cadherin gene transcription, further supporting the anti-metastatic activity of this compound [8]. These results are consistent with the data from literature disclosing for PPAR $\gamma$ a protective role in in vitro and in vivo colorectal cancer (CRC) models [9-13]. In the gastrointestinal tract, in fact, PPAR $\gamma$ impairs cellular proliferation, stimulates differentiation and induces apoptosis [14]. Both in sporadic CRCs and rodent models PPAR $\gamma$ hampers tumor initiation/progression acting as a tumor suppressor [15]. CRC derived cells and transplanted tumors in nude mice undergo growth inhibition, G0/G1 arrest and caspaseactivated apoptosis and differentiation upon treatment with selective ligands, such as thiazolinediones (TZDs) or 15-deoxy$\Delta^{12,14}$-prostaglandin $\mathrm{J}_{2}[16,17]$. Moreover, ligand-bound PPAR $\gamma$ regulates lipid and carbohydrate metabolism, adipogenesis, insulin sensitization, inflammation, atherosclerosis [18-20]. It is conceivable that such a wide range of functions implies different binding modalities of the selective ligands to the receptor ligand binding domain (LBD) and interactions with protein partners activating different pathways involved in the control of metabolism, proliferation or differentiation. Such a choice likely depends on the amount of the receptor available in a given cell, the chemical features of the ligands and their affinity for the receptor. The ligands, moreover, induce conformational changes to the PPAR $\gamma$ LBD that influence the recruitment of functional effectors (coactivators, corepressors, molecular adapters, chromatin modifying enzyme activities etc.) that in turn stimulate the formation of an open chromatin and activation of a wide range of gene transcription. Many of these genes are involved in glucose and lipid metabolism, thus TZDactivated PPAR $\gamma$ ameliorates diabetic patients' conditions [21-24]. Unfortunately, these synthetic TZDs cause undesired side- and offtarget effects (higher rate of bone fractures, weight gain, edema, renal function failure, etc.) [25-27]. More recently, identification and characterization of specific PPAR $\gamma$ ligands known as SPPARMs (Selective PPAR $\gamma$ Modulators), displaying beneficial antidiabetic action with no or reduced side-effects, are gaining interest [28-30].

In line with this reasoning, to obtain novel molecules that could act as PPAR $\gamma$ agonists and inhibit CRC development, we selected cladosporol B, an oxidate form of cladosporol A, and investigated its antiproliferative and proapoptotic properties in comparison with cladosporol A (Fig. 1). Here, we demonstrate that cladosporol B displays anticancer activity in HT-29 cells due to not only a G0/G1 cell cycle arrest via p21 $1^{\text {waf1/cip } 1}$ early overexpression, but also a strong activation of apoptosis as evidenced by experiments in different cell lines in the presence of GW9662, a specific PPAR $\gamma$ inhibitor. The effects of cladosporol $B$ are more pronounced than those of cladosporol A and correlate with a lower affinity for the PPAR $\gamma$ LBD and a reduced PPRE-mediated transactivation potential. Surface plasmon resonance (SPR) experiments and site-specific $\operatorname{PPAR} \gamma$ mutants confirmed these conclusions. Proton nuclear magnetic resonance $\left({ }^{1} \mathrm{H}\right.$ NMR) and high resolution electrospray ionization mass (HR-ESI-MS) were used to elucidate the epoxide ring opening reaction of cladosporols $\mathrm{A}$ and $\mathrm{B}$ in dimethyl sulfoxide (DMSO) $/ \mathrm{H}_{2} \mathrm{O}$ system to form the corresponding PPAR $\gamma$ active compounds $\mathbf{2 A}$ and 2B. Moreover, we report and compare the 3D structures of the PPAR $\gamma$ LBD in the complex with $\mathbf{2 A}$ and 2B, providing a molecular explanation for their different behavior as full and partial $\operatorname{PPAR} \gamma$ agonists, respectively. The stronger antiproliferative activity of cladosporol B might correlate with a differential binding to the PPAR $\gamma$ LBD as compared to cladosporol A.
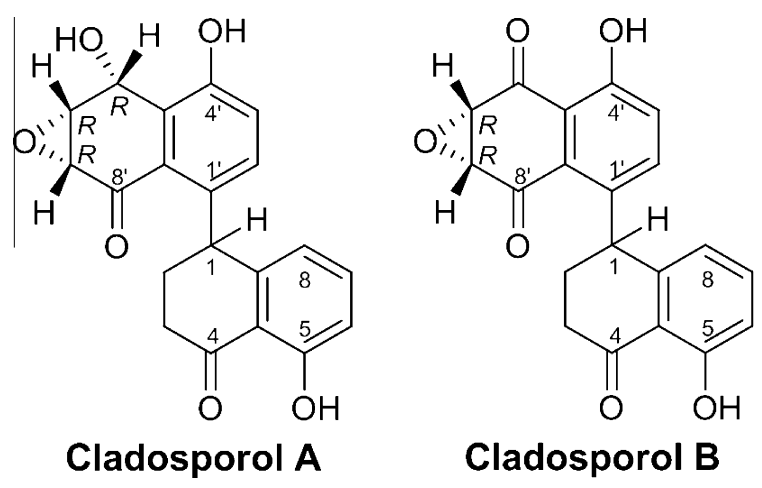

Fig. 1. Chemical structures of cladosporol A and B.

\section{Materials and methods}

\subsection{Cells, antibodies and reagents}

HT-29, RKO and HEK293 cells were obtained from the American Type Culture Collection (Rockville, MD, USA). HT-29 cells bear different genetic abnormalities typical of human CRC, such as a mutated Tp53 (Arg 273 His) and a wild-type RAS allele [31].

Antibodies against $\mathrm{p} 21^{\text {waf1/cip1 }}, \beta$-actin and caspase 3 precursor were purchased from Santa Cruz Biotechnology (Santa Cruz, CA, USA). Anti-mouse and anti-rabbit IgG peroxidase-linked secondary antibodies, ECL and ECL Plus Western blotting detection kit were purchased from Amersham Life Science (Little Chalfont, Buckinghamshire, UK). D-MEM (Dulbecco's Modified Eagle's Medium), D-luciferin sodium salt, trichloroacetic acid, propidium iodide (PI), rosiglitazone (RGZ) and GW9662 were from Sigma Aldrich (St. Louis, MO, USA). Fetal bovine serum (FBS), penicillinstreptomycin, L-glutamine, trypsin-EDTA and OptiMEM I were obtained from Gibco (Carlsbad, CA, USA). Charcoal/dextran-treated FBS was purchased from Hyclone (Logan, Utah, USA). Fetal calf serum (FCS), Lipofectamine 2000, CellTiter Aqueous One Cell Proliferation Assay were obtained from Promega (Madison, WI, USA).

\subsection{Cell culture and cladosporol $A$ and $B$ treatments}

Human colon adenocarcinoma HT-29 or RKO cells were grown as a monolayer in D-MEM containing $10 \% \mathrm{FBS}, 1 \%$ penicillin-streptomycin and $1 \%$ L-glutamine. The cells were cultured in $100 \mathrm{~mm}$ plates, at $70-80 \%$ confluence, in a $5 \% \mathrm{CO}_{2}$ humidified atmosphere, at $37^{\circ} \mathrm{C}$. Cladosporol A and B (Fig. 1) treatments were carried out in the presence of $10 \%$ charcoal/dextran-treated FBS containing $1 \%$ penicillin-streptomycin and 1\% L-glutamine, whereas the cells were maintained at $50 \%$ confluence. Cladosporol A and B were dissolved in DMSO and mixed with fresh medium to achieve the final concentration. In all treatments, the DMSO final concentration in the medium was less than $0.1 \%$. In separate experiments, cells were treated with increasing concentrations of cladosporol A and B, for the indicated times.

\subsection{Cell viability}

The growth rate of HT-29 cells was evaluated using the CellTiter Aqueous One Cell Proliferation Assay (Promega, Madison, WI, USA), as previously described [7]. To further evaluate cell growth after treatment with cladosporol A and B, cells were plated in 12-well plates at a density of $10^{6}$ cells $/ \mathrm{cm}^{2}$. After treatment, the cells were washed with PBS, trypsinized and collected in culture medium. Cell counting was performed as previously reported [7]. 


\subsection{Flow cytometry analysis}

HT-29 cells were plated at similar confluency, as described above, and after $24 \mathrm{~h}$, synchronized by a $48 \mathrm{~h}$ serum deprivation in $0.1 \%$ FBS. An aliquot of the cells was stimulated with 2.5 and $5 \mu \mathrm{M}$ of cladosporol B for different times $(4,8,12,24$ and $48 \mathrm{~h})$ in the presence of D-MEM containing 10\% FBS. Another aliquot of cells was allowed to grow again in the complete medium for the same times; these samples were used as control. After treatment, the evaluation of DNA cell content was performed by FACS analysis as previously described [7].

\subsection{Western blotting analysis}

Treated and untreated cells were lysed in Ripa buffer $(150 \mathrm{mM}$ $\mathrm{NaCl}, 50 \mathrm{mM}$ Tris-HCl, pH 7.6, 10 mM EDTA, 1\% NP-40) containing also a protease inhibitors cocktail and then centrifugated at 17,000 RCF for $10 \mathrm{~min}$, at $4{ }^{\circ} \mathrm{C}$. Supernatant containing total proteins was quantified and $80 \mu \mathrm{g}$ of each sample were separated on $12 \%$ SDS-PAGE. Western blotting assays were carried out as previously reported [7].

\subsection{DNA fragmentation assay}

DNA fragmentation assay was carried out treating HT-29 cells with $20 \mu \mathrm{M}$ cladosporol A and, simultaneously, with $5 \mu \mathrm{M}$ cladosporol B for different times (12, 24, 48 and $72 \mathrm{~h})$. After treatment, the cells were harvested and washed with $1 \mathrm{ml}$ of PBS, resuspended in $100 \mu \mathrm{l}$ of PBS. The cells were spun down at $1000 \mathrm{~g}$, lysed in lysis buffer (Tris- $\mathrm{HCl} 50 \mathrm{mM}$, EDTA $10 \mathrm{mM}, \mathrm{N}-$ lauroylsarcosine $0,5 \%$, proteinase $\mathrm{K} 0.1 \mathrm{mg} / \mathrm{ml}$ ) and incubated for $6 \mathrm{~h}$ at $55^{\circ} \mathrm{C}$. During the incubation RNAase $1 \mu \mathrm{g} / \mathrm{ml}$ was added (Sigma Aldrich, St. Louis, MO, USA). After incubation for $30 \mathrm{~min}$ at $37^{\circ} \mathrm{C}, 3 \mu \mathrm{l}$ of a proteinase $\mathrm{K}$ (Sigma Aldrich, St. Louis, MO, USA) solution was added and incubated for additional $30 \mathrm{~min}$ at $37{ }^{\circ} \mathrm{C}$. Gel loading buffer $(0.25 \%$ bromophenol blue, $0.25 \%$ xylene cyanol, $30 \%$ glycerol) was added and the entire content of the tube transferred to $1.5 \%$ agarose gel and electrophoresed at $2 \mathrm{~V} / \mathrm{cm}$ for $16 \mathrm{~h}$. The DNA present was visualized under UV light after staining with ethidium bromide.

\subsection{Plasmids and transient transfection experiments}

PPAR $\gamma 1$ overexpression was obtained using a PCDNA3 vector carrying a FLAG-tagged complete PPAR $\gamma 1$ cDNA. PPRE-Luc plasmid has a luciferase reporter gene under the transcriptional control of the herpes simplex thymidine kinase (TK) promoter fused to three copies of the PPRE derived from Acyl-CoA oxidase gene. As an internal control for all transient transfection assays, we used the RSV- $\beta$ Gal plasmid, expressing $\beta$-galactosidase gene driven by the strong Rous Sarcoma Virus (RSV) promoter. The day before transient transfection, HEK293 and RKO cells stably expressing FLAGPPAR $\gamma 1$ were plated in 12 -well plates to reach $70 \%$ confluence. After $24 \mathrm{~h}$, growth medium was replaced with OPTI-MEM ${ }^{\circledR}$ I, without serum and antibiotics, and cells were transfected with the luciferase reporter gene (PPRE-Luc) using lipofectamine 2000 reagent according to the manufacturer's instructions. About 10-12 h after transfection, cells were washed and treated with different concentrations of RGZ, cladosporol A and B. The same protocol was used in the cotransfection experiments with FLAG-PPAR $\gamma 1$ wt and its mutated form (C285A). Similar conditions in transfection assays were also used when the cells were treated with GW9662 for the indicated times and dosage. Transfection samples were carried out in triplicate and the transactivation activities evaluated by luciferase assay. The values were normalized by $\beta$-galactosidase assay and the average value for each triplicate was calculated.

\subsection{SPR measurements}

SPR analyses were carried out using a Biacore 3000 optical biosensor (Little Chalfont, Buckinghamshire, UK) according to our previously published procedures [32]. Briefly, a PPAR $\gamma$ LBD surface and a BSA surface were prepared on a research-grade CM5 sensor chips (Little Chalfont, Buckinghamshire, UK). Proteins $(50 \mu \mathrm{g} / \mathrm{ml}$ in $10 \mathrm{mM} \mathrm{CH} \mathrm{CH}_{3} \mathrm{COONa}$, pH 5.3) were immobilized using standard amine-coupling protocols to obtain densities of 5-8 kRU. Cladosporol A and B were dissolved in 100\% DMSO to obtain $4 \mathrm{mM}$ solutions, and then diluted in Phosphate-Buffered Saline (PBS). For each molecule a six-point concentration series spanning $0.025-1 \mu \mathrm{M}$ was set up. Final DMSO concentration was set to $0.1 \%$. SPR experiments were carried out using a $50 \mu \mathrm{l} / \mathrm{min}$ flow rate, at $25{ }^{\circ} \mathrm{C}$. Association and dissociation times were set at $60 \mathrm{~s}$ and $300 \mathrm{~s}$, respectively. To yield kinetics and thermodynamic parameters of complex formation sensorgrams were fit to a single-site bimolecular interaction model using BIAevaluation software (Little Chalfont, Buckinghamshire, UK).

\section{9. ${ }^{1} \mathrm{H}$ NMR and HR-ESI-MS analysis of cladosporols A and B}

All deuterated solvents (DMSO- $\mathrm{d}_{6}, 99.9$ atom\%; $\mathrm{D}_{2} \mathrm{O}, 99.9$ atom $\%$ ) were purchased from Sigma-Aldrich. ${ }^{1} \mathrm{H}$ NMR spectra were recorded at $25^{\circ} \mathrm{C}$ using a Bruker Avance $600 \mathrm{MHz}$ instrument. DMSO- $\mathrm{d}_{6} / \mathrm{D}_{2} \mathrm{O}$ mixture was used as solvent and TMS as an internal standard. All numbers referring to NMR data obtained are in parts per million ( $\mathrm{ppm}$ ). HR-ESI-MS spectra were obtained by means of a Thermo LTQ Orbitrap XL mass spectrometer. The spectra were recorded by infusion into the ESI source using $\mathrm{MeOH}$ dry as the solvent.

2.9.1. (1aR,7R,7aR)-6,7-Dihydroxy-3-(5-hydroxy-4-oxo-1,2,3,4-tetrahydronaphthalen-1-yl)-7,7a-dihydronaphtho[2,3-b]oxiren-2(1aH)one (cladosporol $A$ )

${ }^{1} \mathrm{H}$ NMR (500 MHz, DMSO-d $\left.\mathrm{d}_{6}\right): \delta 7.36(\mathrm{t}, 1 \mathrm{H} ; J=8.4 \mathrm{~Hz}), 6.98(\mathrm{~d}$, $1 \mathrm{H} ; J=8.6 \mathrm{~Hz}), 6.90(\mathrm{~d}, 1 \mathrm{H} ; J=8.6 \mathrm{~Hz}), 6.77(\mathrm{~d}, 1 \mathrm{H} ; J=8.4 \mathrm{~Hz}), 6.15$ (d, $1 \mathrm{H} ; J=8.4 \mathrm{~Hz}), 5.49(\mathrm{~s}, 1 \mathrm{H}), 4.79(\mathrm{~m}, 1 \mathrm{H}), 4.02(\mathrm{dd}, 1 \mathrm{H} ; J=4.5$, $2.1 \mathrm{~Hz}), 3.83(\mathrm{~d}, 1 \mathrm{H} ; J=4.5 \mathrm{~Hz}), 2.75(\mathrm{~m}, 2 \mathrm{H}), 2.27(\mathrm{~m}, 2 \mathrm{H}), \mathrm{ppm}$. Mass: $m / z=353(\mathrm{M}+\mathrm{H}, \mathrm{ESI}+), 100 \%$.

2.9.2. ( $\left.5^{\prime} R, 6^{\prime} R, 7^{\prime} S\right)-4^{\prime}, 5,5^{\prime}, 6^{\prime}, 7^{\prime}-P e n t a h y d r o x y-2,3,6^{\prime}, 7^{\prime}$-tetrahydro-[1, $1^{\prime}$ - binaphthalene $-4,8^{\prime}\left(1 H, 5^{\prime} H\right)$-dione $(\mathbf{2 A})$

${ }^{1} \mathrm{H}$ NMR (500 MHz, DMSO-d $): \delta 7.38(\mathrm{t}, 1 \mathrm{H} ; J=8.4 \mathrm{~Hz}), 7.08(\mathrm{~d}$, $1 \mathrm{H} ; J=8.8 \mathrm{~Hz}), 6.83(\mathrm{~d}, 1 \mathrm{H} ; J=8.4 \mathrm{~Hz}), 6.68(\mathrm{~d}, 1 \mathrm{H} ; J=8.6 \mathrm{~Hz}), 6.31$ $(\mathrm{d}, 1 \mathrm{H} ; J=8.4 \mathrm{~Hz}), 5.15(\mathrm{~m}, 2 \mathrm{H}), 4.72(\mathrm{~d}, 1 \mathrm{H} ; J=9.8 \mathrm{~Hz}), 3.82(\mathrm{~m}$, $1 \mathrm{H} ; J=9.8,3.1 \mathrm{~Hz}), 2.72(\mathrm{~m}, 2 \mathrm{H}), 2.21(\mathrm{~m}, 2 \mathrm{H})$, ppm. Mass: $m / z=369(\mathrm{M}+\mathrm{H}, \mathrm{ESI}+), 100 \%$.

2.9.3. (1aS,7aR)-3-Hydroxy-6-(5-hydroxy-4-oxo-1,2,3,4-tetrahydronaphthalen-1-yl)naphtho[2,3-b]oxirene-2,7(1aH,7aH)-dione

(cladosporol B)

${ }^{1} \mathrm{H}$ NMR $\left(500 \mathrm{MHz}\right.$, DMSO-d $\left.\mathrm{d}_{6}\right): \delta 7.68(\mathrm{t}, 1 \mathrm{H} ; J=8.4 \mathrm{~Hz}), 7.45(\mathrm{~d}$, $1 \mathrm{H} ; J=8.6 \mathrm{~Hz}), 7.43(\mathrm{~d}, 1 \mathrm{H} ; J=8.6 \mathrm{~Hz}), 6.95(\mathrm{~d}, 1 \mathrm{H} ; J=8.4 \mathrm{~Hz}), 6.33$ $(\mathrm{d}, 1 \mathrm{H} ; J=8.4 \mathrm{~Hz}), 5.10(\mathrm{~m}, 1 \mathrm{H}), 4.36(\mathrm{~m}, 2 \mathrm{H}), 2.90(\mathrm{~m}, 2 \mathrm{H}), 2.43(\mathrm{~m}$, $2 \mathrm{H})$, ppm. Mass: $m / z=351(\mathrm{M}+\mathrm{H}, \mathrm{ESI}+), 100 \%$.

\subsection{4. $4^{\prime}, 5,5^{\prime}, 6^{\prime}, 7^{\prime}, 8^{\prime}$-Hexahydroxy-2,3-dihydro-[1,1'-binaphthalen]-4} (1H)-one (2B)

${ }^{1} \mathrm{H}$ NMR (500 MHz, DMSO-d $\left.\mathrm{d}_{6}\right): \delta 8.70$ (brs), $7.34(\mathrm{t}, 1 \mathrm{H}$; $J=8.6 \mathrm{~Hz}), 6.92(\mathrm{~d}, 1 \mathrm{H} ; J=8.6 \mathrm{~Hz}), 6.82(\mathrm{~d}, 1 \mathrm{H} ; J=8.6 \mathrm{~Hz}), 6.78(\mathrm{~d}$, $1 \mathrm{H} ; J=8.4 \mathrm{~Hz}), 6.16(\mathrm{~d}, 1 \mathrm{H} ; J=8.4 \mathrm{~Hz}), 3.95(\mathrm{~m}, 1 \mathrm{H}), 2.75(\mathrm{~m}, 2 \mathrm{H})$, $2.41(\mathrm{~m}, 2 \mathrm{H})$, ppm. Mass: $m / z=369(\mathrm{M}+\mathrm{H}, \mathrm{ESI}+), 100 \%$. 


\subsection{Computational chemistry}

Molecular modeling and graphics manipulations were performed using Maestro 10.2 (Schrödinger, LLC, New York, NY, 2015, USA) and UCSF-Chimera 1.8.1 software packages (http:// www.cgl.ucsf.edu/chimera) running on a E4 Computer Engineering E1080 workstation provided with a Intel Core i7-930 Quad-Core processor [33]. GOLD 5.2 (CCDC Software Limited: Cambridge, U.K., 2008) was used for all docking calculations [34]. Figures were generated using Pymol 1.0 (Schrödinger, LLC, New York, NY, 2015, USA).

\subsection{Protein and ligand preparation}

The crystal structure of PPAR $\gamma$ complexed with the ligand LT175 (PDB code: 3B3K) [35] was recovered from the Brookhaven Protein Data Bank (PDB), and employed for the automated docking studies. The protein was processed through the Protein Preparation Wizard in Maestro. All crystallographic water molecules and other chemical components were deleted, the right bond orders as well as charges and atom types were assigned and the hydrogen atoms were added to both proteins. Arginine and lysine side chains were considered as cationic at the guanidine and ammonium groups, and the aspartic and glutamic residues were considered as anionic at the carboxylate groups. The imidazole ring of $\mathrm{H} 449$ and $\mathrm{H} 323$ into PPAR $\gamma$ were set in their $\mathrm{N} \varepsilon 2-\mathrm{H}(\mathrm{N}$ tau-H) tautomeric state. Moreover, an exhaustive sampling of the orientations of groups, whose $\mathrm{H}$-bonding network needs to be optimized, was performed. Finally, the protein structure was refined with a restrained minimization with the OPLS2005 force field by imposing a 0.3 A rmsd limit as the constraint.

Molecular structures of compounds $\mathbf{2 A}$ and $\mathbf{3 B}$ were built using the fragment dictionary of Maestro and preprocessed with LigPrep 3.4 (Schrödinger, LLC, New York, NY, 2015, USA) which prepares the ligands in multiple protonation and tautomerization states at a neutral $\mathrm{pH}$. Compounds were then optimized by Macromodel 10.8 (Schrödinger, LLC, New York, NY, 2015, USA) using the MMFF force field with the steepest descent (1000 steps) followed by truncated Newton conjugate gradient (500 steps) methods. Partial atomic charges were computed using the OPLS-AA force field.

\subsection{Docking simulations}

Docking of 2A and 3B into PPAR $\gamma$ LBD was performed with the GOLD software, which uses a genetic algorithm (GA) for determining the docking modes of ligands and proteins. The coordinates of the cocrystallized ligand LT175 were chosen as active-site origin. The active-site radius was set equal to $8 \AA$. Each GA run used the default parameters of 100,000 genetic operations on an initial population of 100 members divided into five subpopulations, with weights for crossover, mutation, and migration being set to 95, 95 , and 10 , respectively. GOLD allows a user-definable number of GA runs per ligand, each of which starts from a different orientation. For these experiments, the number of GA runs was set to 200 without the option of early termination, and scoring of the docked poses was performed with the original ChemPLP scoring function followed by rescoring with ChemScore [36-40]. The final receptor-ligand complex for each ligand was chosen interactively by selecting the highest scoring pose that was consistent with experimentally-derived information about the binding mode of the ligand.

\subsection{Statistical analysis of the in vitro assays}

All experiments were performed in triplicate with three biological replicates. Data from viability, flow cytometry, Western blotting and transient transfection experiments were expressed as mean \pm SD. Data between two groups were assessed using Student's $t$ test. $P$-values less than 0.05 were considered significant. Particularly, cell viability of Fig. 2A was analyzed comparing
A

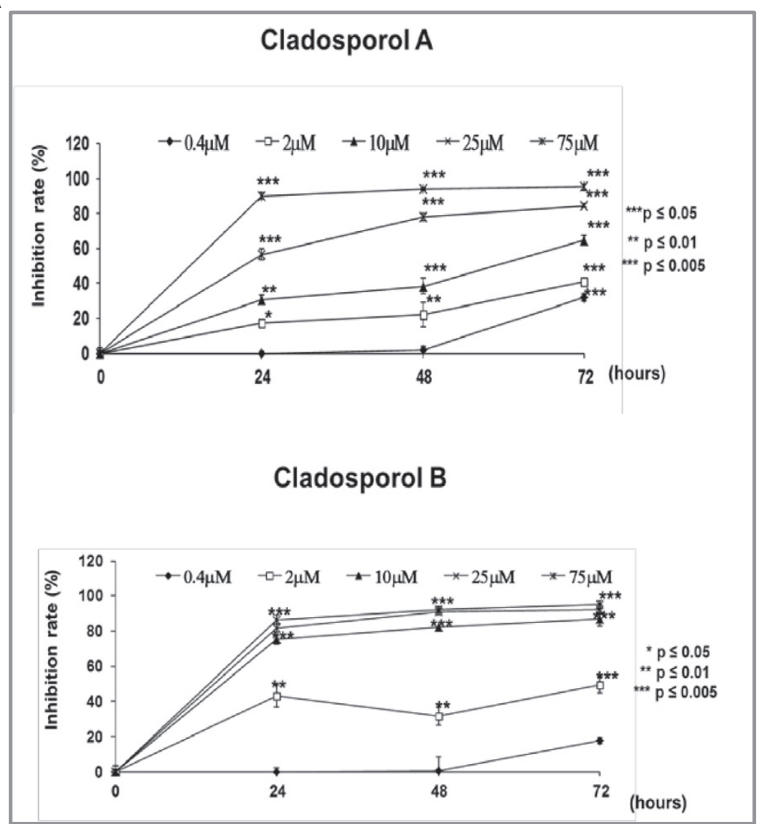

B

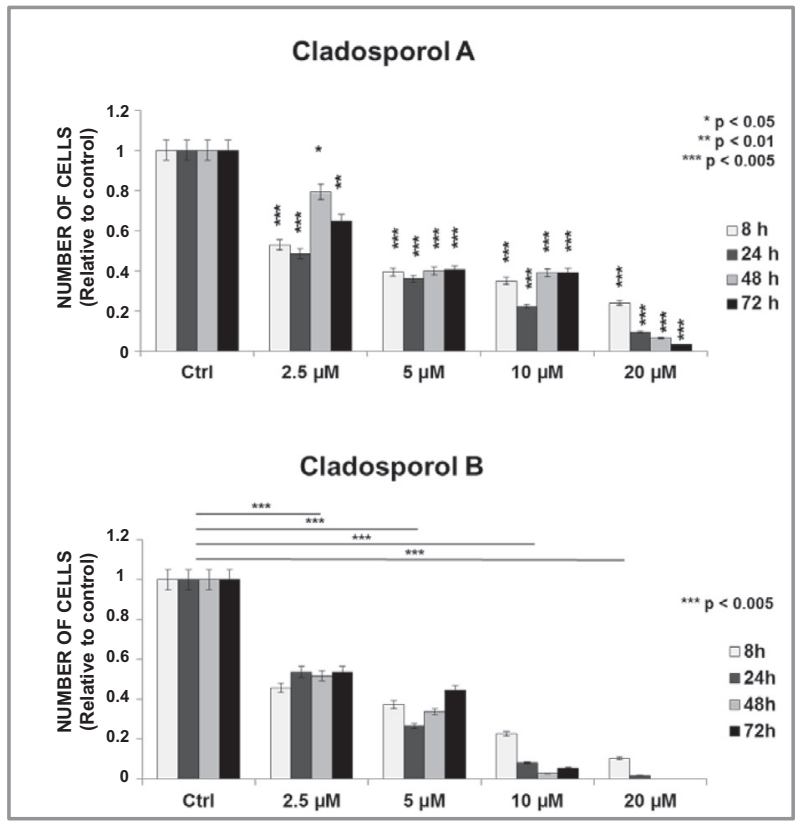

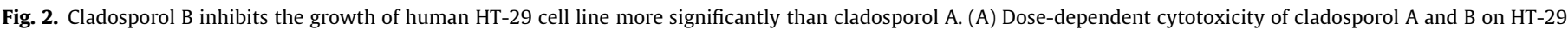

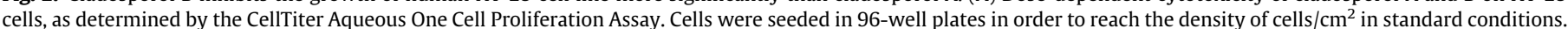

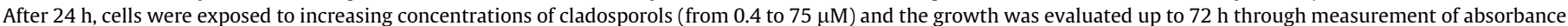

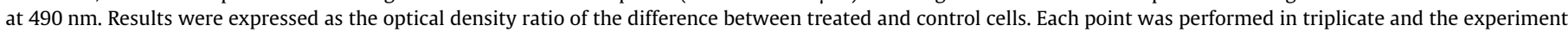

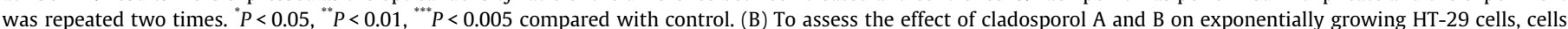

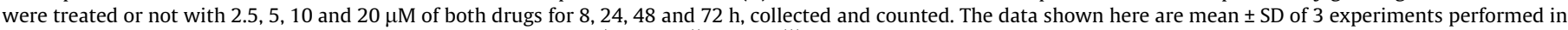
duplicate. Results were similar in two independent experiments. ${ }^{*} P<0.05,{ }^{* *} P<0.01,{ }^{* * *} P<0.005$ compared with control. 
time-dependent concentration effects. A one-Way ANOVA test was performed and referred to time points while Student's test was realized between experimental groups in comparison with the corresponding control. Asterisks reported in the figure show significance degrees, set to $P<0.05$.

\section{Results}

\subsection{Cladosporol B inhibits the growth of human HT-29 cell line}

To investigate whether cladosporol B is endowed with antiproliferative activity as cladosporol A, we assessed the growth of colon carcinoma HT-29 cells treated for different time points (24, 48 and $72 \mathrm{~h}$ ) with increasing concentrations of the compound. Cladosporol B greatly reduced cell proliferation with $\mathrm{IC}_{50}$ values of $2.32 \mu \mathrm{M}$, $3.16 \mu \mathrm{M}$ and $2.03 \mu \mathrm{M}$ for 24,48 and $72 \mathrm{~h}$ long treatments, respectively, as evaluated by the Cell Titer Aqueous One Cell Proliferation Assay (Fig. 2A). In similar experiments, cladosporol A displayed $\mathrm{IC}_{50}$ values of $13.85 \mu \mathrm{M}, 12.35 \mu \mathrm{M}$ and $6.9 \mu \mathrm{M}$ for 24,48 and $72 \mathrm{~h}$ treatments, respectively [7]. To confirm these results, we treated HT-29 cells with increasing concentrations of cladosporol B or A for $8,24,48$ and $72 \mathrm{~h}$ and counted the surviving cells. Their number diminished in a dose- and time-dependent manner as compared to untreated cells; the reduction was particularly evident at the highest concentrations (Fig. 2B); exposure to $10 \mu \mathrm{M}$ cladosporol B for $48 \mathrm{~h}$, indeed, inhibited cell proliferation of about $90 \%$, whereas for cladosporol $A$, at the same dosage and for the same time, the inhibition was about $50 \%$. These results demonstrate that cladosporol $\mathrm{B}$ inhibits cell proliferation more than cladosporol A.

\subsection{Cladosporol B induces a G1-phase growth arrest during cell cycle}

To identify the cell cycle changes underlying the observed growth inhibition, HT-29 cells were cultured in proliferating medium for $24 \mathrm{~h}$, synchronized by serum starvation for $48 \mathrm{~h}$ and exposed to a medium containing 10\% FBS and different concentrations of cladosporol B. Exposure to the compound at 2.5 and $5 \mu \mathrm{M}$ caused a significant increase in the G0/G1 cell population and a concomitant decrease in the S- and G2/M phase populations with respect to untreated cells as assessed by flow cytometry (Fig. 3A). The percentage of G0/G1 cells, after treatment with $2.5 \mu \mathrm{M}$ cladosporol B for $4,8,12 \mathrm{~h}$, was $80.2 \%, 76.2 \%$ and $65.5 \%$, respectively; after treatment with $5 \mu \mathrm{M}$ for the same times, the values were $84.8 \%, 84.6 \%$ and $66.4 \%$; in contrast, the percentage of G0/G1 cell population in proliferating cells taken as a control showed lower values as $76.3 \%, 64.8 \%$ and $45.7 \%$ after 4,8 and 12 h, respectively, suggesting that the treated cells display a delayed entry in the cell cycle. It is conceivable that the decrease in the G0/G1 population observed at 24 and 48 h upon treatment was due to cell cycle withdrawal and enhanced cell death. We already reported that exposure to $20 \mu \mathrm{M}$ cladosporol A caused a significant increase in the G0/G1 phase and a parallel decrease in the $S$ and G2/M phase cell populations [7]. Comparing the results obtained with the two compounds, cladosporol B displays a more powerful activity in arresting HT-29 cell cycle.

To elucidate the molecular mechanisms underlying the reported effects, we assessed the expression of p21 $1^{\text {waf1/cip } 1}$, a specific cell-cycle control protein, by Western blotting assay on extracts from proliferating HT-29 cells treated for different times with increasing concentrations of the drug (Fig. 3B). A slight increase

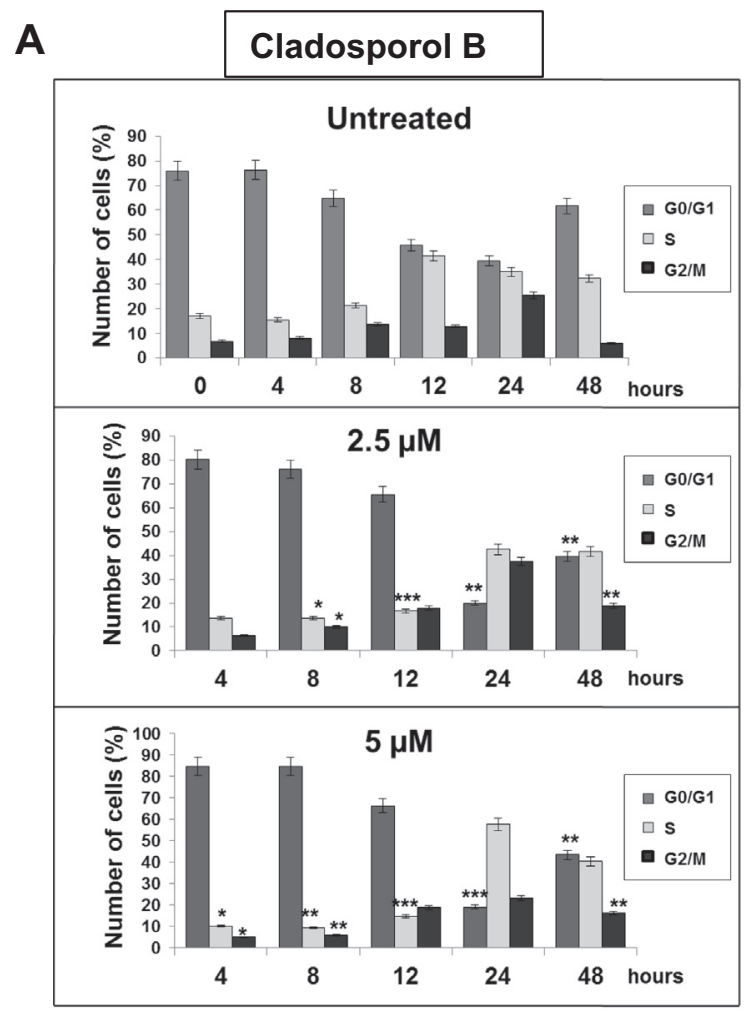

B

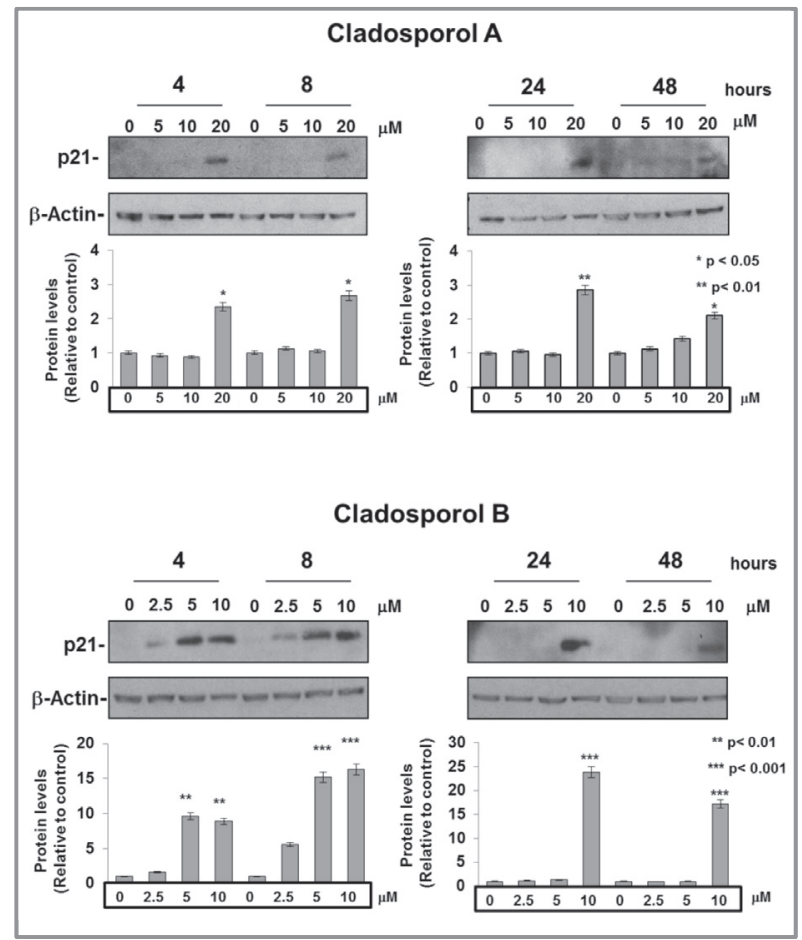

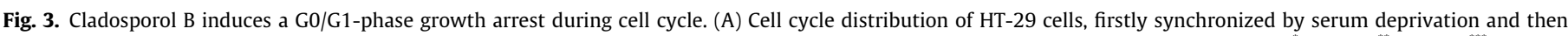

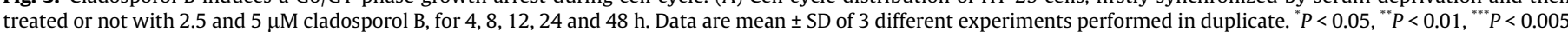

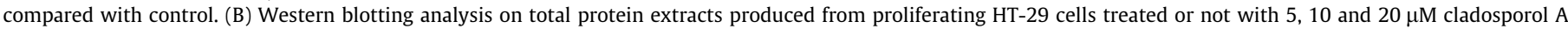

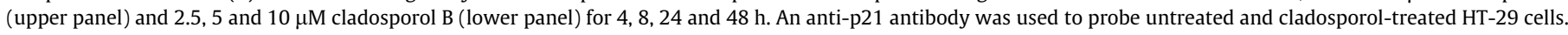

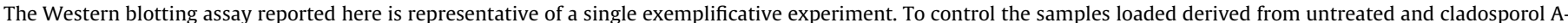

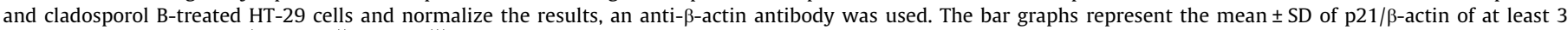
independent experiments. ${ }^{*} P<0.05,{ }^{* *} P<0.01,{ }^{* * *} P<0.001$ compared with control. 
in $\mathrm{p} 21^{\text {waf1/cip } 1}$ expression was already detectable with $2.5 \mu \mathrm{M}$ cladosporol B while it was more robust upon exposure to 5 and $10 \mu \mathrm{M}$ for 4 and $8 \mathrm{~h}$. The elevation was visible even after 24 and $48 \mathrm{~h}$ treatments only with $10 \mu \mathrm{M}$ cladosporol $\mathrm{B}$. In contrast, the increase in $\mathrm{p} 21^{\text {waf } 1 / \mathrm{cip} 1}$ expression occurred only upon exposure to $20 \mu \mathrm{M}$ cladosporol A for $4,8,24$ and $48 \mathrm{~h}$ and was less pronounced. The $\mathrm{p} 21^{\text {waf1/cip } 1}$ levels started to decline to undetectable levels at $48 \mathrm{~h}$ with both compounds. These results indicate that cladosporol $B$ induces a more robust cell cycle arrest than cladosporol A likely due to a stronger stimulation of $\mathrm{p} 21^{\text {waf1/cip1 }}$ expression.

\subsection{Cladosporol B stimulates apoptosis of HT-29 cells}

The progressive reduction in surviving HT-29 cells caused by cladosporol B (2.5 and $5 \mu \mathrm{M})$ and cladosporol A $(20 \mu \mathrm{M})$ (see Fig. 2B) is accompanied by a time- and dose-dependent appearance of a sub-G0/G1 peak, a typical feature of the late phase of apoptosis
(Fig. 4A). Cladosporol B induced a more remarkable increase in this subpopulation than cladosporol A and rosiglitazone (RGZ) a wellknown full PPAR $\gamma$ agonist used as control. To further verify this, the cells were stained with Annexin V-FITC and propidium iodide and analyzed by flow cytometry (Fig. 4B, lower graph): cladosporol $B$ induced a higher number of Annexin +/propidium + cells, i.e. apoptotic cells, than the isoform A. In the same analysis, we also evaluated the amount of necrotic cells following treatment with different doses of cladosporol B. Their number did not significantly change ruling out necrosis as an alternative mode of cell death induced by cladosporol B (Fig. 4B, upper graph). Finally, we analyzed the levels of caspase- 3 precursor, one of the effectors of the apoptotic process. A significant decrease in the caspase- 3 precursor levels was detected in western blot analysis of HT-29 cells treated with both drugs for 12, 24 and $48 \mathrm{~h}$ (Fig. 4C). Caspase-3 activation causes maturation of CAD (caspase-activated deoxyribonuclease) that, in turn, produces DNA fragmentation. Cladosporol B displayed a higher degradative activity than cladosporol $\mathrm{A}$ in accordance with

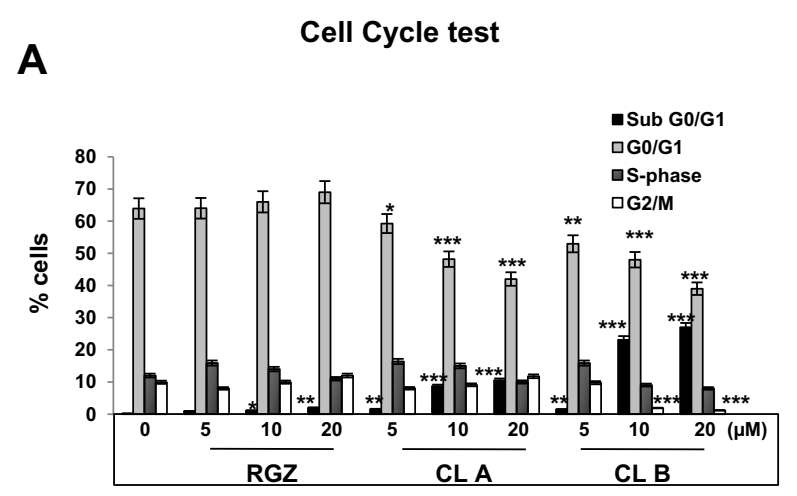

C

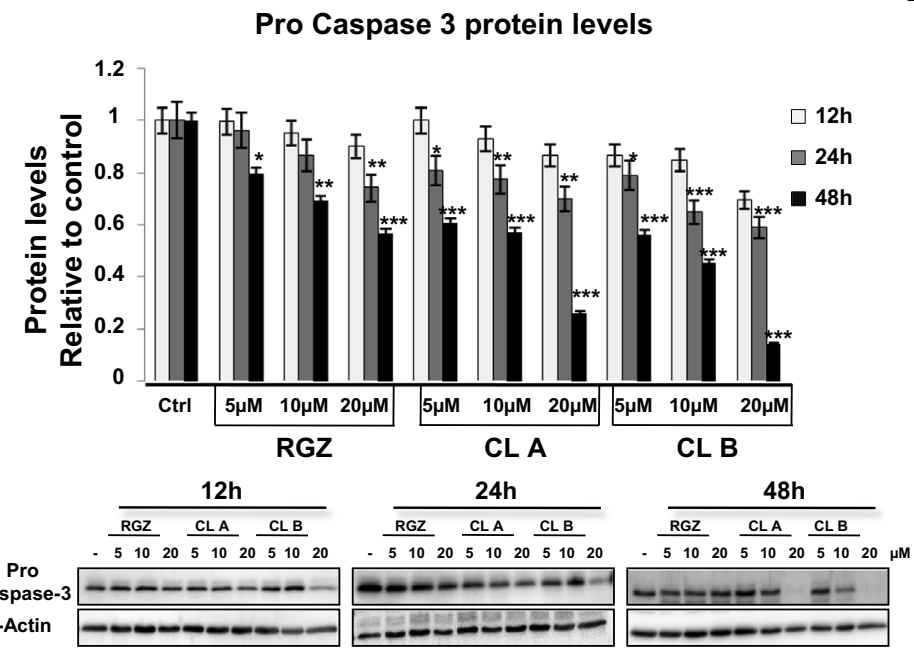

B

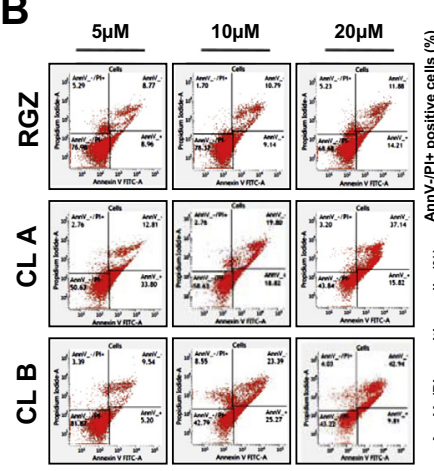

Apoptosis assay

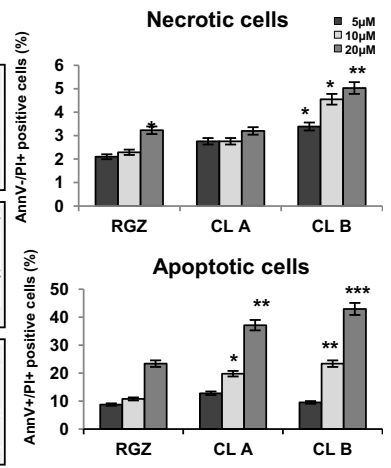

D

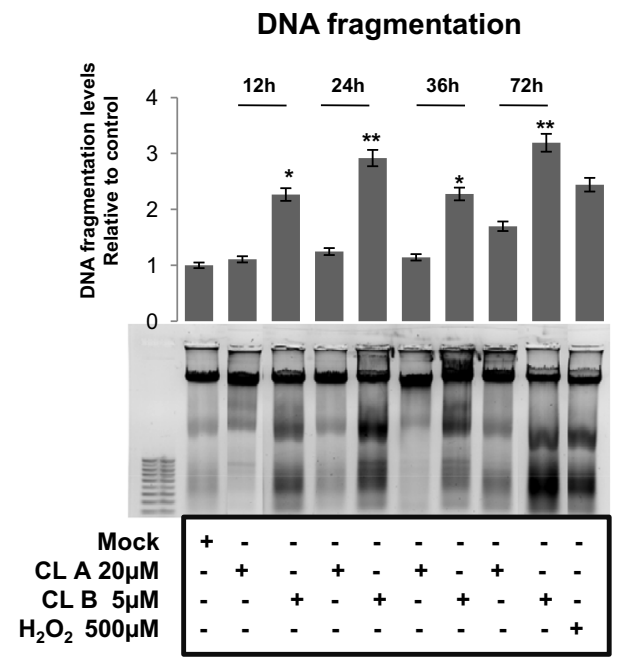

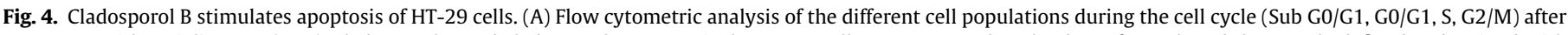

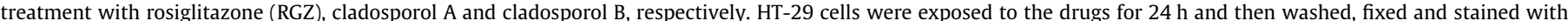

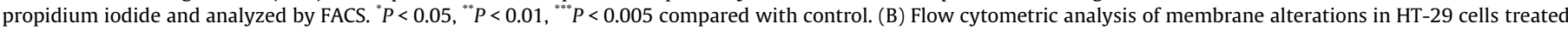

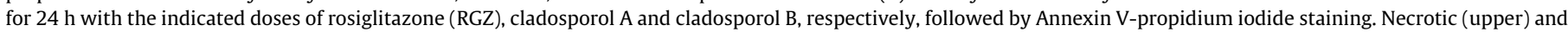

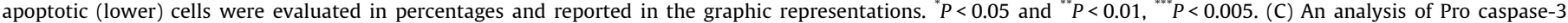

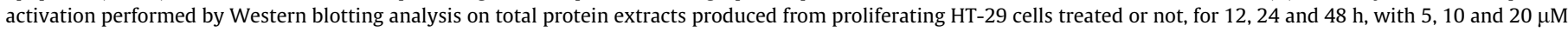

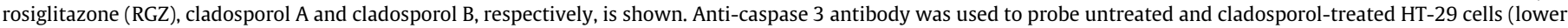

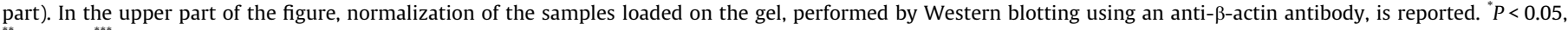

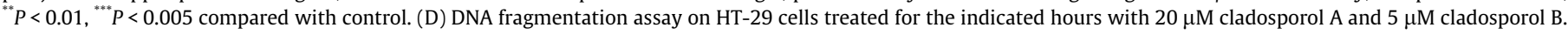

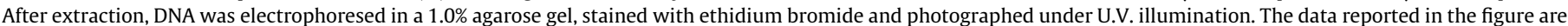

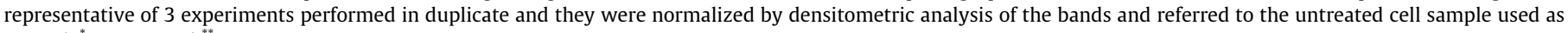
control. ${ }^{*} P<0.05$ and ${ }^{* *} P<0.01$. 
the results above reported (Fig. 4D). Altogether the results demonstrate that cladosporol B displays a stronger proapoptotic activity than cladosporol A.

\subsection{Cladosporol B displays a different PPAR $\gamma$-mediated transcriptional activity than cladosporol $A$}

We previously reported that cladosporol A acts as a PPAR $\gamma$ ligand and inhibits CRC cell proliferation through modulation of expression of several cell cycle gatekeepers, cell cycle arrest at the G1/S transition and $\beta$-catenin/T-cell factor (TCF) pathway inactivation $[7,8]$. To verify that also cladosporol B acts as a PPAR $\gamma$ ligand and investigate possible differences between the two compounds, we transiently transfected HEK293 cells that stably express an exogenous PPAR $\gamma 1$ with the PPRE-TK-luc-reporter plasmid. Luciferase activity was measured in the cell extracts upon treatment for different times with rosiglitazone, cladosporol A and $B$, respectively. Cladosporol A displayed the same potency and efficacy as rosiglitazone, a well-known synthetic ligand of PPAR $\gamma$ (Fig. 5A). Cladosporol B, instead, showed a lower transactivation activity suggesting that cladosporols bind the PPAR $\gamma$ LBD with a different strength, with cladosporol A that may be considered a full agonist, and cladosporol $\mathrm{B}$ a partial agonist.

To prove that cladosporols A and B are bona fide PPAR $\gamma$ ligands and to assess their binding affinity, we employed a surface plasmon resonance (SPR)-based approach [41]. The acquired sensorgrams showed that both compounds interact with the protein (Fig. 5B). Kinetic and thermodynamic parameters of the interactions were calculated for each molecule fitting the experimental curves to a classical $A+B=A B$ model. Specifically, a thermodynamic dissociation constant $\left(K_{\mathrm{D}}\right)$ of $1.19 \mu \mathrm{M}$ and a kinetic dissociation constant $\left(k_{\text {off }}\right)$ of $1.5 \times 10^{-3} \mathrm{~s}^{-1}$ were obtained for cladosporol $A$, suggesting that this compound forms a quite stable complex with PPAR $\gamma$ LBD. A similar behavior was observed for cladosporol $\mathrm{B}$, even if the measured $K_{\mathrm{D}}(59.2 \mu \mathrm{M})$ and $k_{\text {off }}\left(7.8 \times 10^{-2} \mathrm{~s}^{-1}\right)$ revealed a significantly lower affinity for PPAR $\gamma$. These data were referred to those obtained with RGZ as control $\left(K_{\mathrm{D}} 0.320 \mu \mathrm{M}\right.$ and $k_{\text {off }} 2.86 \times 10^{-2} \mathrm{~s}^{-1}$ ).

To further demonstrate that cladosporols act through PPAR $\gamma$, we used GW9662, an irreversible inhibitor of this receptor. Cotreatment of HEK293 cells with rosiglitazone (RGZ) and GW9662 caused a lower transactivation than that induced by rosiglitazone-bound PPAR $\gamma$ alone (Fig. 5C). A similar reduction
A

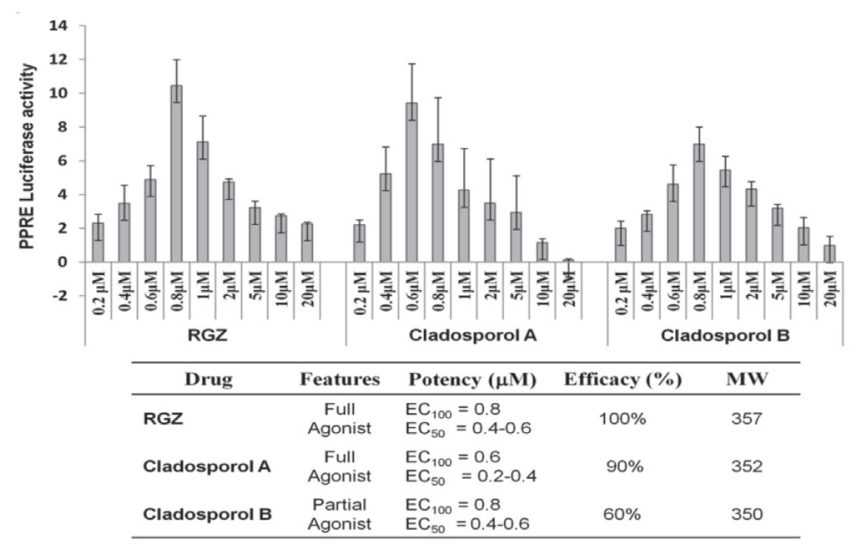

B
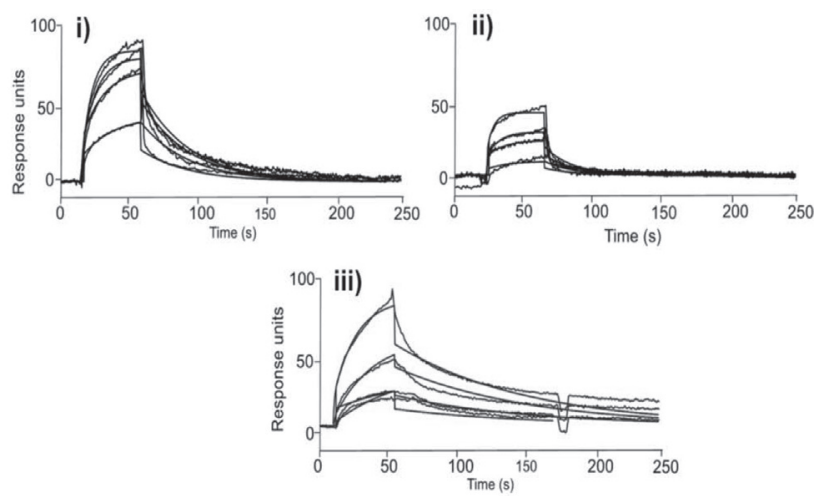

C

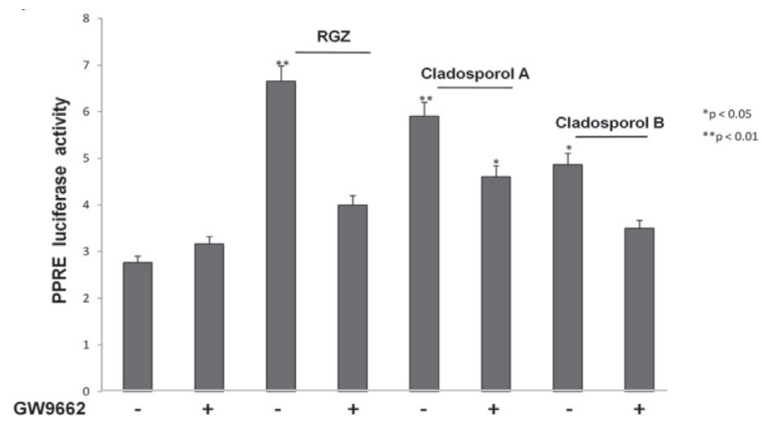

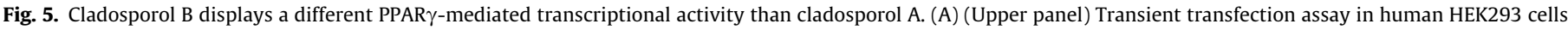

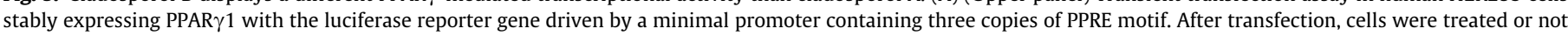

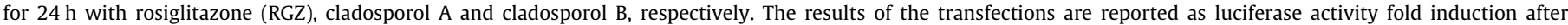

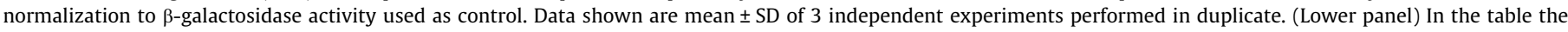

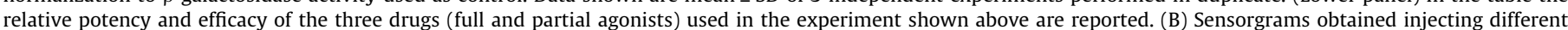

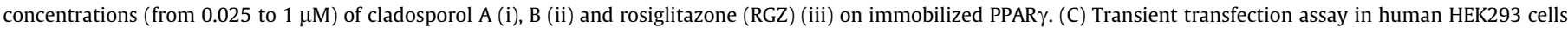

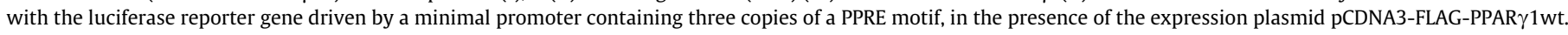

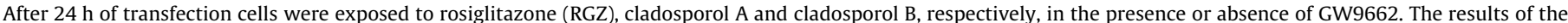

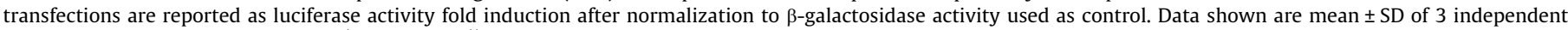
experiments performed in duplicate. ${ }^{*} P<0.05$ and ${ }^{* * *} P<0.01$. 
(even if smaller than rosiglitazone) was observed when the cells were pretreated with GW9662 and than exposed to cladosporol $A$ and $B$, suggesting that these latter ligands can bind only an empty PPAR $\gamma$ LBD. Altogether these results demonstrate that cladosporol A and B bind PPAR $\gamma$ with a different affinity, likely involving different domains of the binding pocket and ensuing activation of different biological pathways.

\subsection{Proapoptotic activity of cladosporol $B$ is dependent upon PPAR 1 activation}

To demonstrate that cladosporol B stimulates apoptosis through the binding to and activation of PPAR $\gamma$, we cultured a human CRC derived cell line RKO that displays very low PPAR $\gamma 1$ expression and a derived clone overexpressing an exogenous PPAR $\gamma 1$ (Fig. 6A), in the presence of rosiglitazone (RGZ), cladosporol A and cladosporol B, respectively, for $24 \mathrm{~h}$. After treatment, cells were stained with Annexin V-FITC and propidium iodide and analyzed by flow cytometry (Fig. 6B): cladosporol B induced a higher number of Annexin +/propidium + cells, i.e. apoptotic cells, than the isoform $A$ and rosiglitazone in both cellular types. In addition, in PPAR $\gamma 1$ overexpressing-RKO cells, the stron- ger proapoptotic activity induced by cladosporol B was significantly reduced by exposure to GW9662 suggesting a PPAR $\gamma$ dependence.

To further demonstrate that PPAR $\gamma$ is significantly involved in the cell proliferation arrest affecting p21 expression, we analyzed total protein extracts from proliferating RKO cells treated for $8 \mathrm{~h}$ with $5 \mu \mathrm{M}$ cladosporol $\mathrm{A}$ and $\mathrm{B}$, in the presence or absence of GW9662. The results reported in Fig. 6 C demonstrate that a significant accumulation of $\mathrm{p} 21^{\text {waf } 1 / \mathrm{cip} 1}$ protein was due to PPAR $\gamma$, as it was greatly reduced upon GW9662 treatment. The results also indicate that the $\mathrm{p} 21^{\text {waf } 1 / \mathrm{cip} 1}$ increase was partly due to PPAR $\gamma$ independent mechanisms. We conclude that cladosporol $B$ induces cell cycle arrest through elevation of p21 waf1/cip1 expression and induction of apoptosis through PPAR $\gamma$-dependent and -independent mechanisms.

\subsection{Ring opening of epoxy-containing cladosporol $A$ and cladosporol $B$} by $\mathrm{DMSO} / \mathrm{H}_{2} \mathrm{O}$

As cladosporols A and B contain a highly polar and tensioned three-membered epoxide ring, they can undergo ring opening reactions with a broad range of electrophiles and nucleophiles, as
A
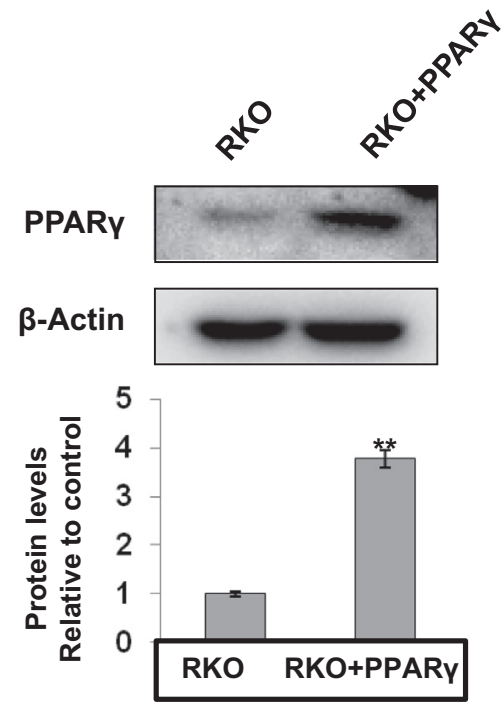

B

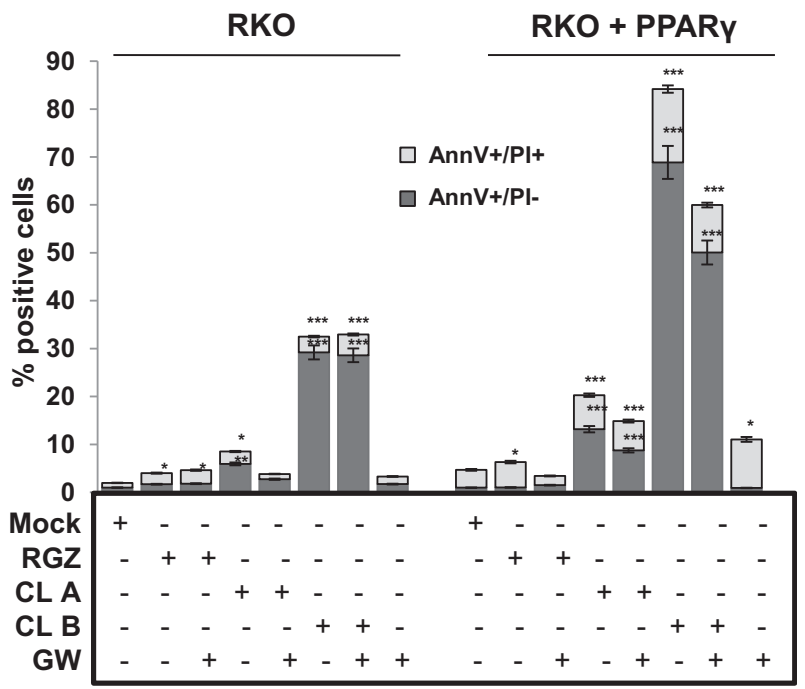

C

p21 protein levels
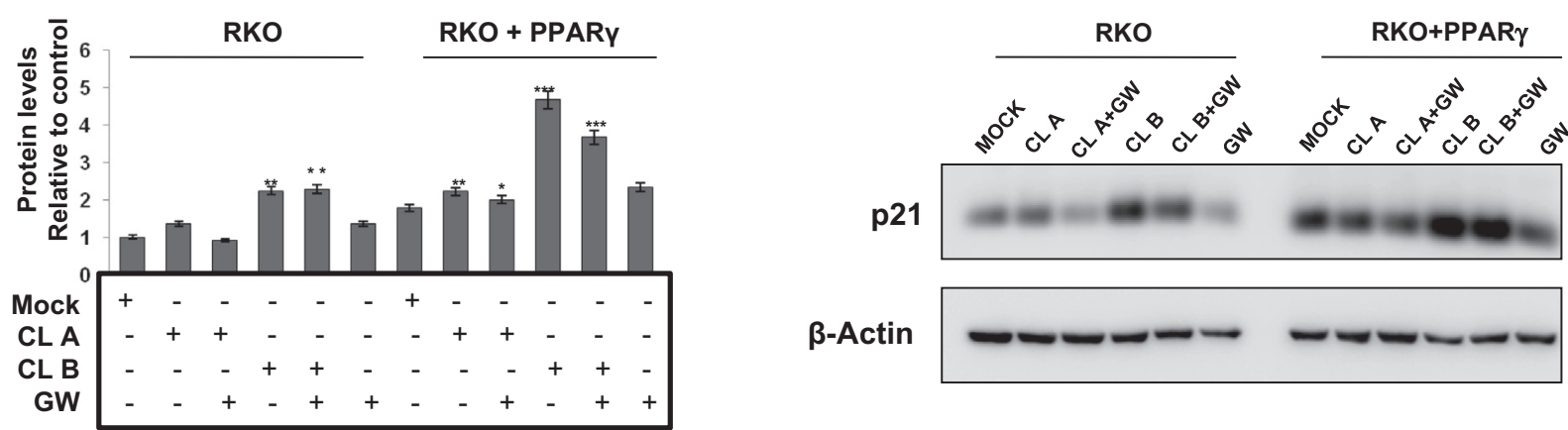

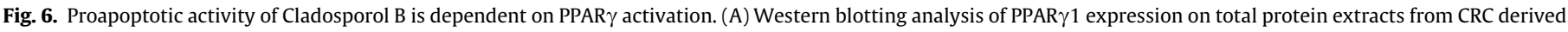

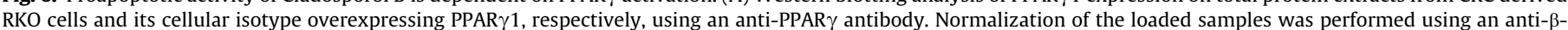

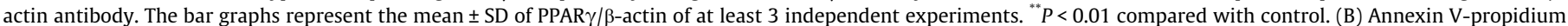

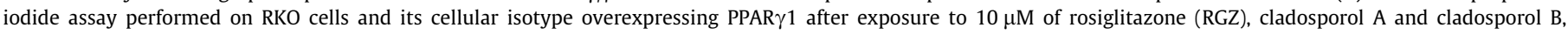

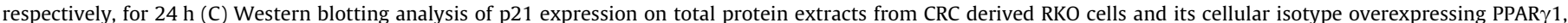

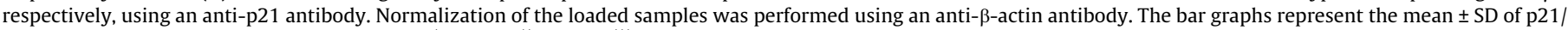
$\beta$-actin of at least 3 independent experiments. ${ }^{*} P<0.05,{ }^{* * *} P<0.01,{ }^{* * *} P<0.005$ compared with control. 
well as with neutral water via an uncatalyzed mechanism. Since in vitro experiments were carried out with both cladosporols dissolved in DMSO, due to their insolubility in other biocompatible solvents, we examined the DMSO effect on two compounds to establish whether their biological activity depends on the epoxide or diol form.

It is well known that DMSO-based nucleophilic epoxide ring opening leads to an unstable hydroxyalkoxysulfonium intermediate $[42,43]$ which in the presence of water is converted into a trans 1,2-diol or a hydroxycarbonyl compound (Fig. 7A).

Therefore, cladosporols $\mathrm{A}$ and $\mathrm{B}$ were dissolved in $\mathrm{D}_{2} \mathrm{O} / \mathrm{DMSO}-$ $\mathrm{d}_{6}(1: 1, v / \mathrm{v})$ and analyzed for $24 \mathrm{~h}$ at $25^{\circ} \mathrm{C}$ by ${ }^{1} \mathrm{H}$ NMR spectroscopy. The spectra were recorded every hour and the peak integrated areas were compared with that obtained with tetramethylsilane (TMS) used as an internal standard. After $2 \mathrm{~h}$, a new species appeared in the two solutions, which was hypothesized to be the sulfate ester of cladosporol A (compound $\mathbf{1 A}$ in Fig. 7B) and cladosporol $B$ (compound $\mathbf{1 B}$ in Fig. 7B) based on the ${ }^{1} \mathrm{H}$ NMR spectra (Fig. 8). The integral ratio of cladosporol A:1A was $1: 3$ after $5 \mathrm{~h}$ and $1: 9$ after $10 \mathrm{~h}$, whereas that of cladosporol B:1B was $1: 2$ after $5 \mathrm{~h}$ and $2: 5$ after $10 \mathrm{~h}$. The structural differences between the two epoxide-containing compounds may be responsible for the observed differences in the yield of the sulfonium intermediate. The ring opening rate of the hydroxyepoxide cladosporol A seems to be faster than that of the ketoepoxide cladosporol $B$. Further addition of $\mathrm{D}_{2} \mathrm{O}$ in the NMR tubes yielded the trans diol $\mathbf{2 A}$ and hexahydroxy-dihydro-(1,1'-binaphthalen)-4-one (2B) (Fig. 8).

After $24 \mathrm{~h}$, the NMR mixtures, lyophilized and dissolved in methanol dry, were analyzed by high resolution electrospray ionization mass (HR-ESI-MS). The mass spectrum of cladosporol A showed peaks at $453 \mathrm{~m} / \mathrm{z}\left([\mathrm{M}+\mathrm{Na}+\mathrm{H}]^{+}, 100 \%\right), 371 \mathrm{~m} / \mathrm{z}$ $\left(\left[\mathrm{M}-\mathrm{DMSO}-\mathrm{H}_{2}+\mathrm{H}\right]^{+}, 30 \%\right)$ and $353 \mathrm{~m} / \mathrm{z}\left([\mathrm{M}-\mathrm{DMSO}+\mathrm{H}]^{+}, 30 \%\right)$ corresponding to the hydroxyalkoxysulfonium sodiated ion (1A), pen tahydroxy-tetrahydro-(1,1'-binaphthalene)-4,8'-dione (2A in Fig. 7B), and cladosporol A, respectively. The spectrum of the solution containing cladosporol B gave a molecular peak at $429 \mathrm{~m} / z$ ([M $+\mathrm{H}]^{+} 100 \%$ ) corresponding to the hydroxyalkoxysulfonium ion (1B) and a peak at $369 \mathrm{~m} / \mathrm{z}\left([\mathrm{M}-\mathrm{DMSO}+\mathrm{H}]^{+} 40 \%\right)$ corresponding to derivative $\mathbf{2 B}$.

Fig. 7B illustrates a possible mechanism of degradation of cladosporols $A$ and $B$ in DMSO $/ \mathrm{H}_{2} \mathrm{O}$ to compounds $\mathbf{2 A}$ and $\mathbf{2 B}$. When
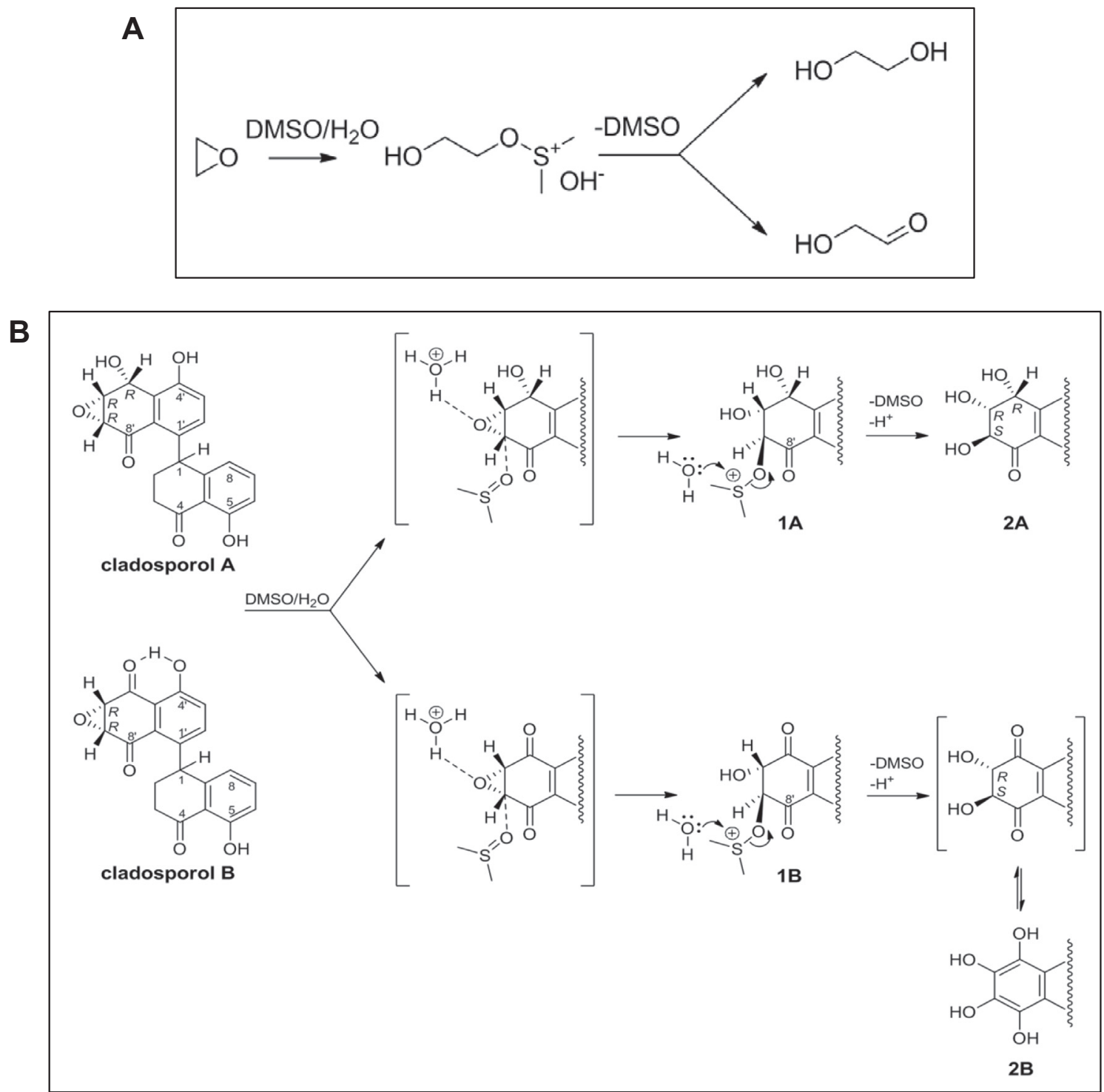

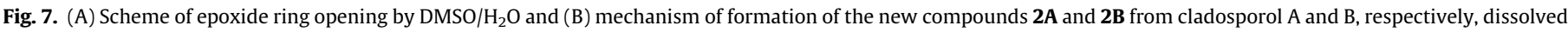
in DMSO/ $\mathrm{H}_{2} \mathrm{O}$. 
A
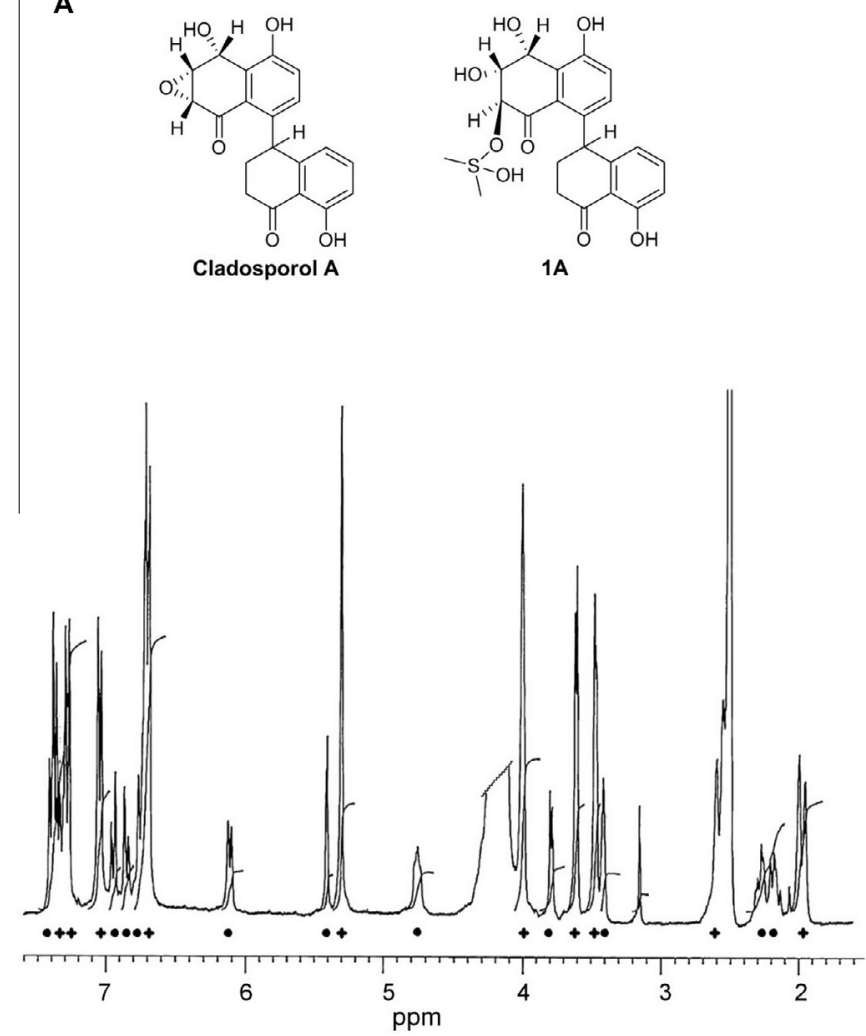
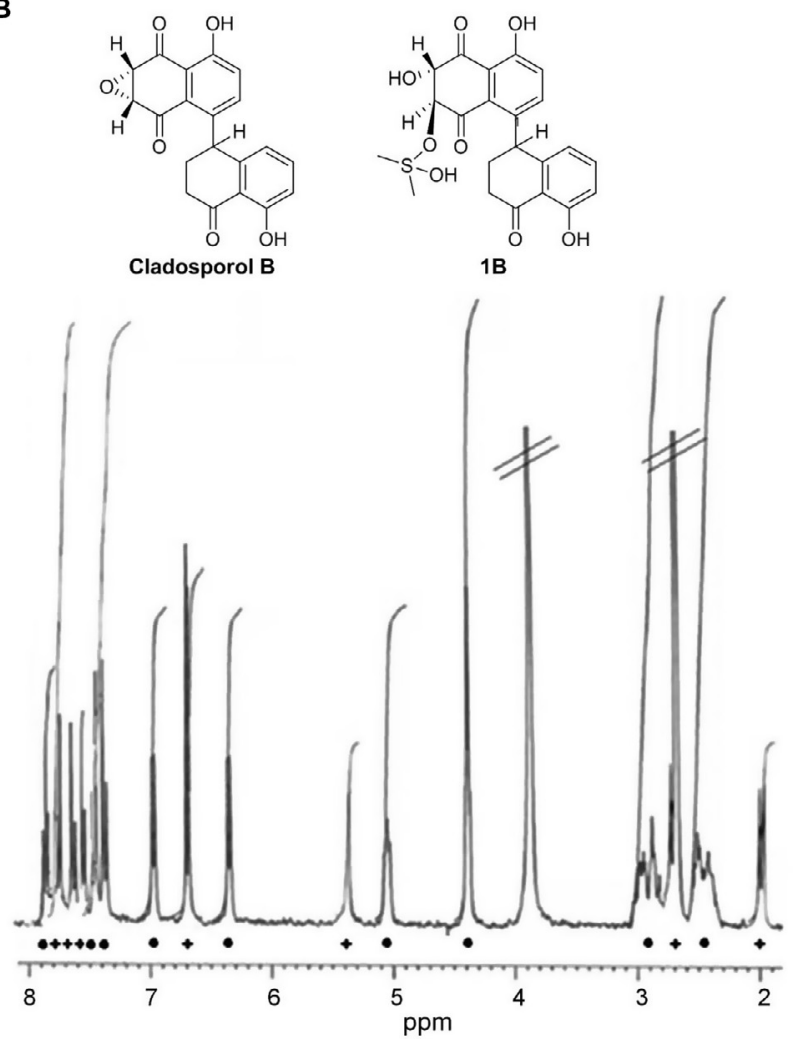

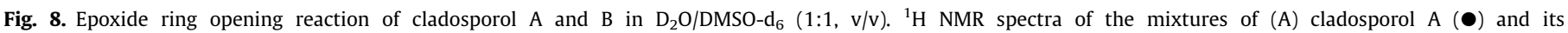
hydroxyalkoxysulfonium intermediate $\mathbf{1 A}(\mathbf{+})$ and of $(\mathrm{B})$ cladosporol $\mathrm{B}(\mathbf{0})$ and its hydroxyalkoxysulfonium intermediate $\mathbf{1 B}(\mathbf{+})$.

cladosporols A and B are attacked by DMSO in a protic medium, the epoxide oxygen is protonated and the $\mathrm{C}-\mathrm{O}$ bond is preferably cleaved between the nucleophile and the adjacent carbon. According to Parker and Isaacs [44] the $8^{\prime}-C=0$ group of the $\alpha, \beta$ unsaturated system favors the attack of DMSO on the adjacent $7^{\prime}-\mathrm{C}$ carbon. It is to note that in cladosporol B an intramolecular $\mathrm{H}$-bond between the $5^{\prime}-\mathrm{C}=\mathrm{O}$ and the $4^{\prime}-\mathrm{OH}$ groups decreases the conjugating effect of the $5^{\prime}-\mathrm{C}=0$ group on the epoxide ring, forcing the DMSO to attack on the same $7^{\prime}-\mathrm{C}$ carbon, as reported above for cladosporol $A$. The formation of hydroxyalkoxysulfonium intermediates (1A and 1B) can be rationalized as a "borderline $\mathrm{SN}_{2}$ mechanism" $[44,45]$. This pathway predicts backside attack of DMSO with inversion at the $7^{\prime}-C$ carbon atom, which can provide the most developing carbonium ion character in the transition state. The hydrolysis of the hydroxyalkoxysulfonium intermediates occurs by attack of water exclusively to sulfur, yielding compounds $\mathbf{2 A}$ and $\mathbf{2 B}$, respectively. This is in agreement with the results from the above described NMR and mass spectral analyses.

\subsection{Docking of compounds $\mathbf{2 A}$ and $\mathbf{2 B}$ into PPAR $\gamma$ binding pocket}

To clarify the molecular mechanism underlying the full or partial agonism of $\mathbf{2 A}$ and $\mathbf{2 B}$, respectively, toward PPAR $\gamma$, we undertook docking studies into the PPAR $\gamma$ LBD. Docking runs were performed with the GOLD 5.2 program [34], in combination with the ChemPLP scoring function followed by rescoring with ChemScore [46]. Docking experiments were carried out using the X-ray crystallographic structure of PPAR $\gamma$ bound to compound LT175 (PDB code: 3B3K) [35].

Compounds 2A and 2B were able to bind PPAR $\gamma$ in a fashion that is distinct from the binding mode of TZDs, such as RGZ, and appears to be more similar to that of LT175. Although TZDs bind in a perpendicular fashion to helix $3(\mathrm{H} 3)$, partially wrapping around H3, compounds $\mathbf{2 A}$ and $\mathbf{2 B}$ bind in a north-south orienta- tion, parallel to H3. Fig. 9A shows the positioning of $\mathbf{2 A}$ into the canonical ligand-binding pocket of PPAR $\gamma$. The 3-OH of the cyclohexenone ring can form a trifurcated $\mathrm{H}$-bond with $\mathrm{Y} 473 \mathrm{OH}$, Y327 $\mathrm{OH}$, and $\mathrm{H} 449 \mathrm{~N} \varepsilon 2$ groups; this latter group engages the ligand $4-\mathrm{OH}$ in a further $\mathrm{H}$-bond. The $5-\mathrm{OH}$ is at $\mathrm{H}$-bonding distance from the $\mathrm{C} 285 \mathrm{SH}$ group on H3. PPAR $\gamma$ full agonists, such as TZDs, generally engage canonical $\mathrm{H}$-bonds with the three residues H323, H449, and Y473 on the inner surface of helix 12 (H12). These interactions stabilize $\mathrm{H} 12$ and are responsible for $\operatorname{PPAR} \gamma$ transactivation $[47,48]$. The 5-OH-dihydronaphthalenone moiety of $\mathbf{2 A}$ is deeply inserted into a specific pocket of the LBD, previously named "diphenyl pocket" [35] thereby forming several favorable hydrophobic interactions. The bottom of the cavity is delimited by the loop $11 / 12$ and is contoured sidewise by $\mathrm{H} 3$ and $\mathrm{H} 11$. Inside the cavity, the 5-OH-dihydronaphthalenone moiety interacts with L453 of H11, L465 of loop 11-12, and Q286 of H3. Specifically, the amino group of Q286 makes an amino-aromatic van der Waals contact with the benzofused ring of the ligand [49]. A favorable van der Waals contact is also realized by the dihydronaphthalenone moiety and the M463 side chain, thus contributing to stabilize the conformation of the loop 11/12. Furthermore, the benzo-fused ring of the $4^{\prime}, 5^{\prime}, 6^{\prime}, 7^{\prime}$-tetrahydroxydihydronaphthalenone forms favorable hydrophobic and $\pi-\pi$ stacking interactions with F363 (H7) and F282 (H3) side chains. Notice that the F282 side chain, in the LT175 crystal structure, is shifted from the $t$ to the folded $g^{*}$ conformation owing to the rigid and straight diphenyl group of the ligand [35]. Superposition of the 2A/PPAR $\gamma$ complex on the RGZ/PPAR $\gamma$ (PDB code 2PRG) and LT175/ $\operatorname{PPAR} \gamma$ crystal structures shows that the benzo-fused ring of the 5$\mathrm{OH}$-dihydronaphthalenone, together with the distal aromatic ring of LT175, occupies the same region normally occupied by F282 in the apo-form of the receptor, thus contributing to stabilize the region including the loop 11/12 [50] (Fig. 9B). It is well known that differences in the hydrophobic packing of this loop may contribute 
A

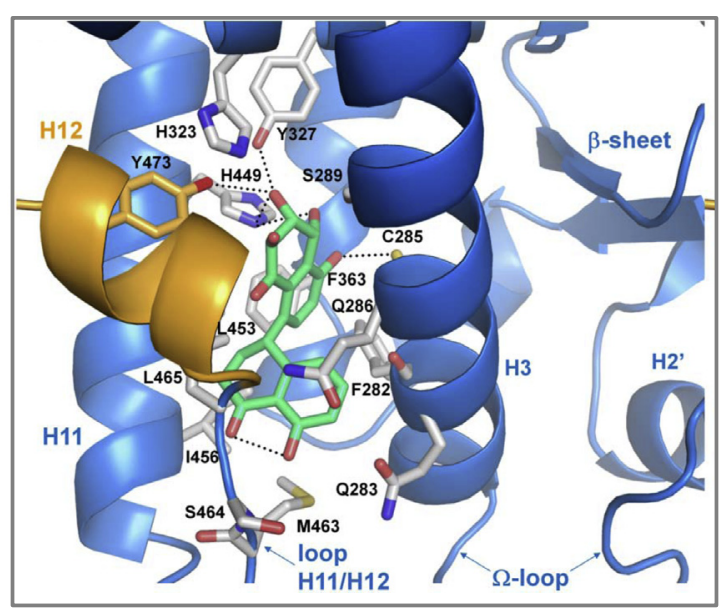

C

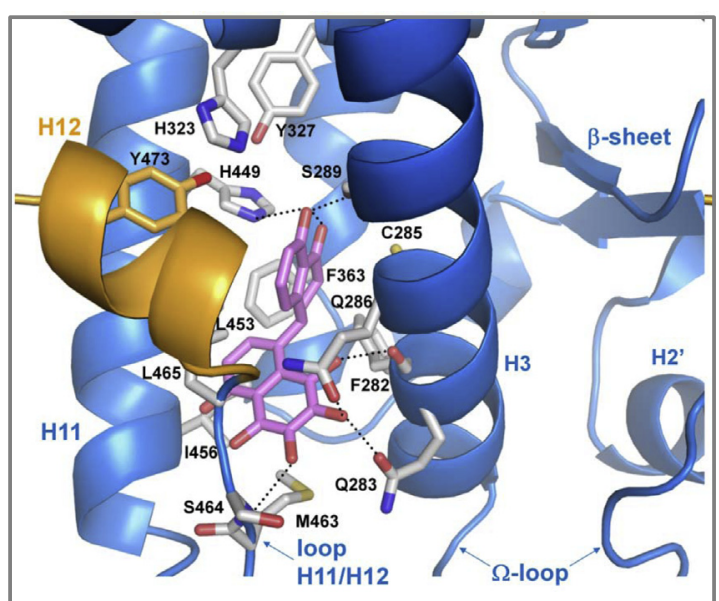

B

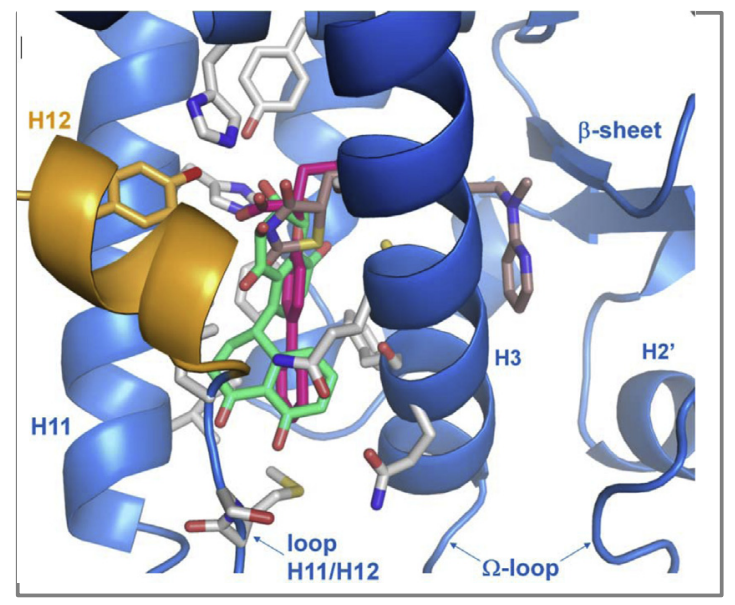

D

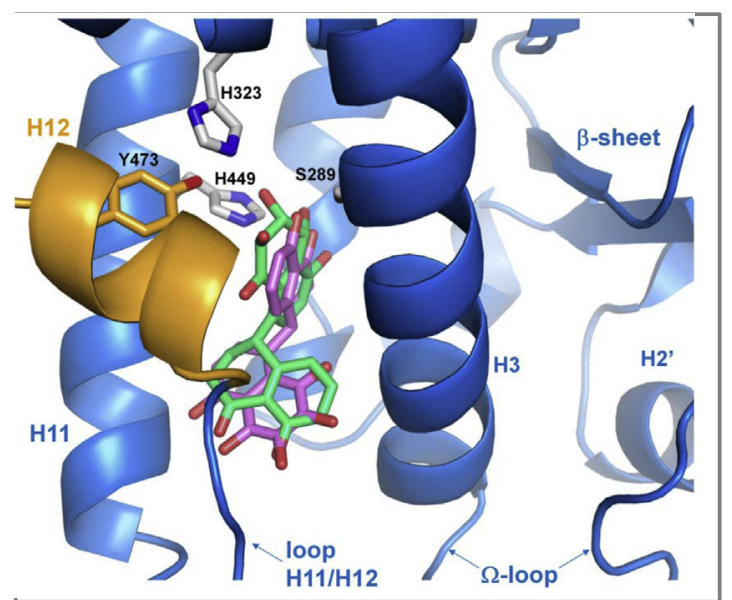

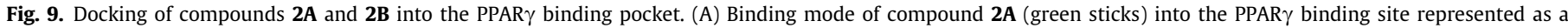

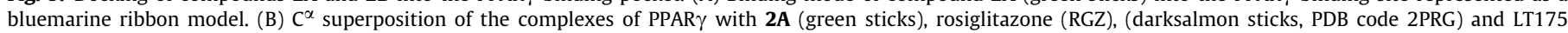

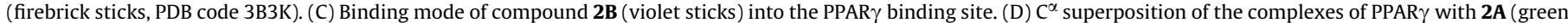

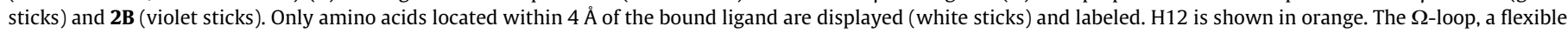

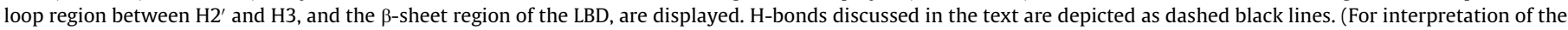
references to color in this figure legend, the reader is referred to the web version of this article.)

to diverse H12 dynamics [51]. Thus, the potency of $\mathbf{2 A}$ is a direct consequence of a very effective stabilization of $\mathrm{H} 12$, through hydrophobic and electrostatic interactions, thus facilitating the recruitment of coactivators.

Surprisingly, docking experiments of compound $\mathbf{2 B}$ revealed a different binding mode to PPAR $\gamma$ in comparison to compound $\mathbf{2 A}$. This compound occupies the same binding location of $\mathbf{2 A}$, but adopts an inverted conformation with the 5-OH-dihydronaphthalenone moiety in proximity of the triad H323, H449 and Y473, and the naphthalene-pentaol nucleus placed in the PPAR $\gamma$ internal cavity (Fig. 9C). A $C^{\alpha}$ superposition of the 2A/PPAR $\gamma$ and 2B/PPAR $\gamma$ complexes is shown in Fig. 9D. The 5-OH group, which is involved in a buried intramolecular $\mathrm{H}$-bond with the 4-keto group of the ligand, maintains a correct position to act as a weak $\mathrm{H}$-bond acceptor from the $\mathrm{H} 449 \mathrm{~N}^{\varepsilon 2} \mathrm{H}$ imidazole ring and a weak H-bond donor to the S289 $\mathrm{OH}$ group. From the opposite side, the naphthalene-pentaol system makes a number of $\mathrm{H}$-bonds with residues of $\mathrm{H} 3$ and loop 11/12. In particular, the $8^{\prime}-\mathrm{OH}$ establishes a $\mathrm{H}$-bond with the backbone $\mathrm{C}=\mathrm{O}$ of F282 (H3), the $7^{\prime}-\mathrm{OH}$ donates $\mathrm{H}$-bonds to the amide $\mathrm{C}=\mathrm{O}$ oxygens of either Q283 or Q286 of $\mathrm{H3}$, and the $6^{\prime}-\mathrm{OH}$ forms a H-bond with the main chain NH of S464 (loop 11/12). Moreover, the ligand forms direct van der Waals contacts with the L453, I456, L465, F282, F363 and M463 residues lining the cavity. It should be noted that also in the case of $\mathbf{2 B}$, the naphthalene-pentaol moiety occupies the same portion of the cavity as the diphenyl group of LT175, between $\mathrm{H} 3$ and the loop 11/12.

Compound 2B makes no direct contacts with residues of $\mathrm{H} 12$, a hallmark of traditional TZDs, but preferentially stabilizes H3 through closer hydrophobic contacts or H-bonds made with residues S289, F282, Q283 and Q286, thus affecting the recruitment of coactivators and transactivation. In fact, it is a partial agonist of PPAR $\gamma$ with a weaker transcriptional activity [52-54]. This relationship is in agreement with our previous findings regarding two enantiomeric ureidofibrate derivatives complexed with PPAR $\gamma$, showing partial and full agonism, respectively, toward this nuclear receptor [52]. Even in that case, while the full agonism of one enantiomer could be related to stronger interactions with $\mathrm{H} 11, \mathrm{H} 12$, and the loop 11/12, the partial agonism of the other enantiomer could be ascribed to closer contacts with residues of $\mathrm{H} 3$.

\subsection{Activity of cladosporols $A$ and $B$ does not require PPAR $\gamma$ C285}

The C285 residue in the PPAR $\gamma$ ligand-binding site is essential for the activity and covalent binding of some PPAR $\gamma$ agonists such as $15 d-\mathrm{PGJ}_{2}$ [55] or partial agonists such as SR2017 (manuscript in preparation) but not for RGZ. Because PPAR $\gamma$ C285 may be important for a noncovalent interaction with both cladosporols (compounds $\mathbf{2 A}$ and $\mathbf{2 B}$ ), as inferred from the docking results, we 
A

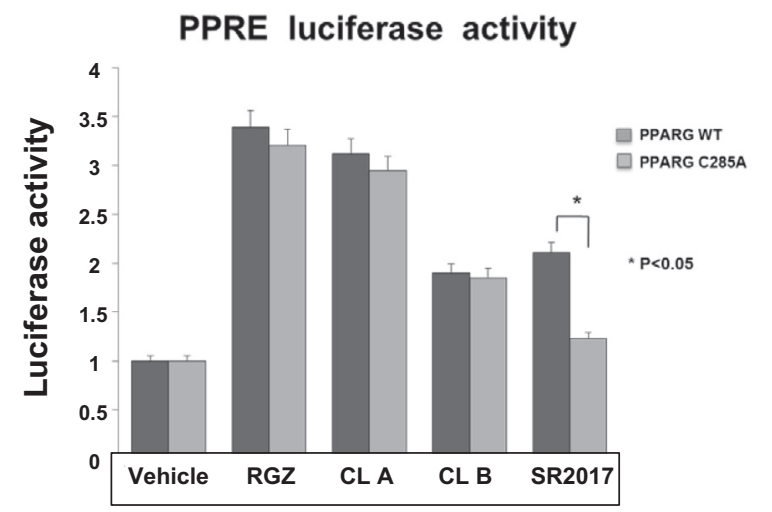

B

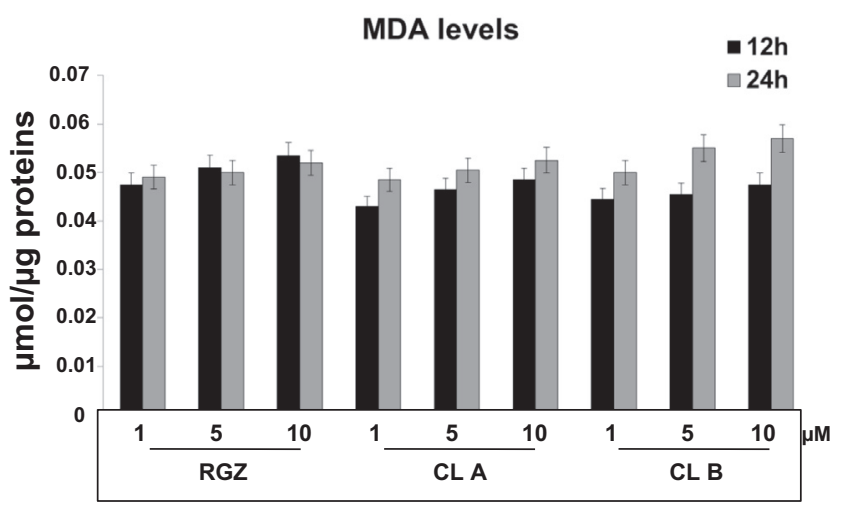

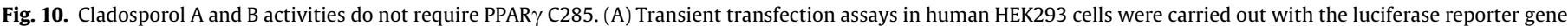

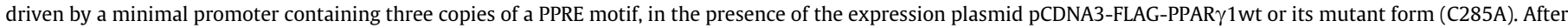

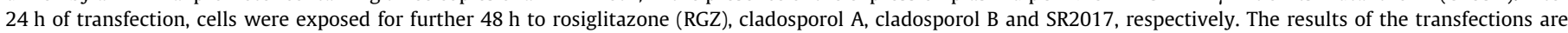

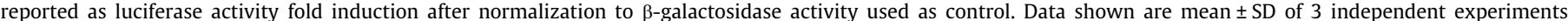

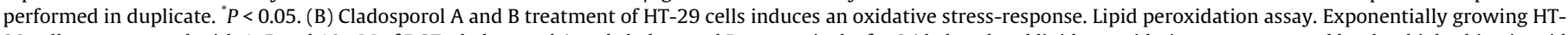

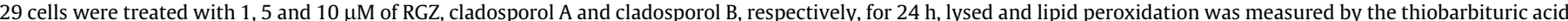

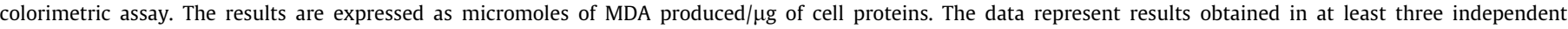
experiments; the error bars indicate standard deviations.

transfected the PPRE-Luc reporter plasmid and the expression vectors for the wild type or a mutant form (C285A) of PPAR $\gamma 1$ into HEK293 cells exposed or not to cladosporol A and B. Luciferase activity from cells transfected with the mutant (C285A) was similar to that from wild type PPAR $\gamma 1$ upon treatment with cladosporol B (2B); a slight reduction was observed upon treatment with cladosporol A (2A) (Fig. 10A). This result implies that the PPAR $\gamma$ activity of both cladosporols does not depend on the C285 residue.

\subsection{Cladosporol A and B treatment of HT-29 cells induces an oxidative stress-response}

We have previously shown that cladosporol A stimulates an oxidative stress via different mechanisms and induces an adaptative response through activation of the ERK and JNK pathways [7]. To prove that the parallel treatment with cladosporol A and $B$ was able to enhance the redox species, we assessed malondialdehyde (MDA) production through a lipid peroxidation assay. Both cladosporols increased the reactive oxygen species (ROS) with cladosporol B (compound 2B) producing a greater accumulation and confirming the induction of a more intense redox response than cladosporol A (compound 2A) (Fig. 10B). These results clearly indicate that both compounds $\mathbf{2 A}$ and $\mathbf{2 B}$ dissolved in DMSO and water show a powerful oxidative ability and stimulate a strong apoptotic response, in agreement with the formation of free radical species for the co-presence of oxidated and reduced species (see Fig. 7B).

\section{Discussion}

Nuclear receptors generally interact with small molecules that stimulate (agonists) or inhibit (antagonists) their biological function. The ligand-mediated activation of NRs strictly depends on the three-dimensional changes of the LBD structure dictated by the positional dynamics of the C-terminal $\mathrm{H} 12$ and the overall AF2 activation domain [56]. Stabilization of H12 and, consequently, presentation of the interacting surface necessary for the displacement of corepressors and concurrent recruitment of coactivators, in fact, induce transcriptional activation of target genes. This scheme applies also to PPARs [50,57]; in this case, ligands can induce either a full or a partial response, triggering pathways involved in diverse cellular processes. Structural studies of ligand-bound PPARs, indeed, are crucial to understand how this interaction influences the dynamics of the local protein domains and which biological responses may be affected in terms of efficiency of gene expression activation (genomic response) or ability of the receptor to interact with different protein partners (nongenomic response). For these reasons, up to date full or partial agonists and antagonists responsible for the wide spectrum of actions of PPARs (including the PPAR $\gamma$ isoform) have been recognized [57].

The data reported in the present study demonstrate that the epoxide ring-opened derivatives $\mathbf{2 A}$ and $\mathbf{2 B}$, generated by the corresponding cladosporols $\mathrm{A}$ and $\mathrm{B}$ when dissolved in DMSO/water (Fig. 7B), act as bona fide PPAR $\gamma$ ligands as documented by transactivation assays and SPR analysis (Fig. 5). In particular, we provide evidence that they differentially bind the PPAR $\gamma$ LBD eliciting distinctive, biological responses (Figs. 2-4 and 6). We define here for the first time the molecular interactions occurring between these natural ligands and the different functional amino acids lining the PPAR $\gamma$ LBD. Specifically, we found that compound 2A (Fig. 9B) interacts with PPAR $\gamma$ differently from RGZ, but similarly to LT175, a synthetic partial PPAR $\gamma$ ligand [35]. RGZ, in fact, usually binds in a perpendicular fashion to $\mathrm{H} 3$, partially wrapping around the helix; compound $\mathbf{2 A}$, instead, binds in a north-south orientation, and runs in parallel with $\mathrm{H} 3$. The ligand engages canonical $\mathrm{H}$-bonds with residues Y473, H449, and H327 on the inner surface of H12, and stabilizes the region including the loop 11/12, thus contributing to establish the network of contacts required for ordering the activation of $\mathrm{H} 12$ that allows recruitment of coactivators [51]. Although the binding of $\mathbf{2 A}$ to the receptor is different from RGZ, the resulting biological properties are comparable: in fact, both molecules exhibit similar sensorgrams at SPR, activate PPAR $\gamma$ and stimulate transcription of a PPRE-driven luciferase reporter gene at the same extent (Fig. 5A and B). The potency and the efficacy of compound $\mathbf{2 A}$ indeed appear to be a direct consequence of a very effective stabilization of H12. Furthermore, we have already shown that cladosporol A, and hence its derivate compound $\mathbf{2 A}$, displays anticancer activities in various human colon cancer cell lines, through modulation of several cell cycle gatekeepers gene expression (p2 $1^{\text {waf1/cip1 }}$, cyclin D1, cyclin E, CDK2, CDK4) [7,8], as reported in RGZ-treated cells [16,17]. 
Unexpectedly, docking experiments of the epoxide ring-opened compound 2B into PPAR $\gamma$ (Fig. 9C) revealed a different binding mode. This compound, in fact, occupies the same location as $\mathbf{2 A}$, but adopts an inverted conformation with the 5-OHdihydronaphthalenone moiety in proximity of the triad Y473, $\mathrm{H} 449$ and $\mathrm{H} 323$, and the naphthalene-pentaol nucleus placed in the PPAR $\gamma$ more internal cavity (Fig. 9D). Interestingly, this compound makes no direct contacts with $\mathrm{H} 12$ residues, a hallmark of traditional TZDs, but preferentially stabilizes $\mathrm{H} 3$ through closer hydrophobic contacts or $\mathrm{H}$-bonds made with residues of this helix (S289, F282, Q283 and Q286), likely affecting coactivator recruitment and transactivation potential [52-54]. Consistently, compound 2B may be considered a PPAR $\gamma$ partial agonist and indeed displays a weaker transactivation profile than 2A (Fig. 5). PPAR $\gamma$ agonists such as $15 \mathrm{~d}_{-} \mathrm{PGJ}_{2}$ [55] or partial agonists such as SR2017 (manuscript in preparation), but not rosiglitazone, require C285 to covalently bind PPAR $\gamma$, whereas the transactivation activity of both cladosporols $\mathrm{A}$ and $\mathrm{B}$ does not depend on this cysteine residue (Fig. 10A).

One of the key questions about the molecular mechanisms of PPAR $\gamma$ action is how various ligands can affect the recruitment of different coregulators that, in turn, differentially stimulate transcription of selected groups of genes [20]. Multiple PPAR $\gamma$ coactivators have been identified so far, but it seems unlikely that each coactivator may regulate a single pathway; more conceivably, diverse coregulators cooperate to activate gene transcription. The identification of SPPARMs implies a different affinity for the ligand-bound receptor to achieve partial or full activation $[20,58]$. This differential result could be due to the conformational changes of the PPAR $\gamma$ LBD induced by ligands unveiling a dynamic response of the receptor. Finally, recent studies have shown that, upon binding of specific ligands, the interactions between PPAR $\gamma$ and coregulators often depend on their amount present in a given cell, explaining why a ligand can function as a partial or full agonist [59-61]. On the basis of these considerations, it is tempting to speculate that the differential binding of cladosporol A and $B$ (more specifically, 2A and 2B) to PPAR $\gamma$ may influence the choice of coregulators through conformational changes induced onto the LBD that may account for the different pathways they regulate. More experiments using PPAR $\gamma$ mutants in transactivation, coimmunoprecipitation and ChIp assays are required to highlight these aspects of our research. These in vitro experiments will likely provide more cues and verify whether the binding of cladosporol B (compound 2B) to PPAR $\gamma$ and the conformational changes of the LBD induced may affect the WNT/TCF/ $\beta$-catenin pathway. We have already demonstrated that a cladosporol A-bound PPAR $\gamma$ physically interacts with $\beta$-catenin stimulating its proteasomal degradation and subsequent inactivation of downstream target genes. E-cadherin, accordingly, is upregulated reinforcing cell-cell interactions $[8,62]$.

A ligand-activated PPAR $\gamma$ controls both the intrinsic and extrinsic arms of the apoptotic pathways [63]. We already demonstrated the inhibitory effects of cladosporol A on HT-29 cell proliferation, suggesting the existence of a regulatory circuit that culminates into cell growth inhibition [7]. We also proposed that ROS generation was due to the activation of NADPH oxidase, the main enzymatic machinery responsible for the production of oxidant species [7]. A TZD-activated PPAR $\gamma$ has been reported to activate transcription of the proline oxidase/proline dehydrogenase (POX/ PRODH) gene, generating mitochondrial superoxide production and triggering apoptosis through both the mitochondrial and death receptor pathways [64]. In addition to being more active than $\mathbf{2 A}$ in arresting HT-29 cell cycle, compound 2B induced also a more robust apoptosis and a more intense redox response (Fig. 10). These latter stronger properties of compound 3B (Figs. 2-4) might be due to its partial agonism and to the differential redox response.
We cannot exclude at the moment that cladosporols A and B may differentially activate POX/PRODH gene transcription, triggering different levels of apoptosis. Additional experiments will be necessary to detail the changes of the apoptotic pathways induced by cladosporols.

In summary, we report here for the first time the identification of a natural compound, cladosporol B, that acts as a PPAR $\gamma$ partial agonist. By different means we show that cladosporol B behaves differently from its reduced form (cladosporol A) with a lower transactivation potential but a higher antiproliferative and antiapoptotic activity. Epoxide-containing cladosporols $\mathrm{A}$ and $\mathrm{B}$ are unstable in DMSO $/ \mathrm{H}_{2} \mathrm{O}$ solution, converting completely to the ring-opened compounds $\mathbf{2 A}$ and $\mathbf{2 B}$. Their structures were confirmed via ${ }^{1} \mathrm{H}$ NMR and HR-ESI-MS. The analysis of the structural features of the binding to the PPAR $\gamma$ LBD shows that cladosporol $B$ interacts differently from full agonists cladosporol A and rosiglitazone. This diverse mode of binding may influence the structure of the LBD and the recruitment of transcription complexes activating distinct pathways. This study may pave the way to identify and further characterize novel natural compounds endowed with stronger biological activities than synthetic and natural available ligands without the undesired side-effects.

\section{Acknowledgements}

This work was supported by funds from the Ministero dell'Istruzione, Università e Ricerca (MIUR-PRIN 2010-2011 prot. 2010W7YRLZ_003) and from DST-University of Sannio (FRA 2013). The authors are grateful to the Centro Interdipartimentale di Analisi Strumentale (CSIAS) dell'Università di Napoli "Federico II".

\section{References}

[1] J.A. Milner, Molecular targets for bioactive food components, J. Nutr. 134 (2004) 2492S-2498S.

[2] C. Chen, A.N. Kong, Dietary cancer-chemopreventive compounds: from signaling and gene expression to pharmacological effects, Trends Pharmacol. Sci. 26 (2005) 318-326.

[3] M.M. Manson, P.B. Farmer, A. Gescher, W.P. Stewar, Innovative agents in cancer prevention, Recent Results Cancer Res. 166 (2005) 257-275.

[4] J. Uzoigwe, E.R. Sauter, Cancer prevention and treatment using combination therapy with plant- and animal-derived compounds, Expert Rev. Clin. Pharmacol. 5 (2012) 701-709.

[5] A. Borriello, D. Bencivenga, I. Caldarelli, A. Tramontano, A. Borgia, A.V. Pirozzi, et al., Resveratrol and cancer treatment: is hormesis a yet unsolved matter? Curr. Pharm. Des. 19 (2013) 5384-5393.

[6] Y. Li, S.M. Meeran, S.N. Patel, H. Chen, T.M. Hardy, T.O. Tollefsbol, Epigenetic reactivation of estrogen receptor-alpha (ERalpha) by genistein enhances hormonal therapy sensitivity in ERalpha-negative breast cancer, Mol. Cancer 12 (2013) 9.

[7] D. Zurlo, C. Leone, G. Assante, S. Salzano, G. Renzone, A. Scaloni, et al., Cladosporol a stimulates G1-phase arrest of the cell cycle by up-regulation of p21(waf1/cip1) expression in human colon carcinoma HT-29 cells, Mol. Carcinog. 52 (2013) 1-17.

[8] D. Zurlo, G. Assante, S. Moricca, V. Colantuoni, A. Lupo, Cladosporol A, a new peroxisome proliferator-activated receptor gamma (PPARgamma) ligand, inhibits colorectal cancer cells proliferation through beta-catenin/TCF pathway inactivation, Biochim. Biophys. Acta 1840 (2014) 2361-2372.

[9] W. Zhang, N. Wu, Z. Li, L. Wang, J. Jin, X.L. Zha, PPARgamma activator rosiglitazone inhibits cell migration via upregulation of PTEN in human hepatocarcinoma cell line BEL-7404, Cancer Biol. Ther. 5 (2006) 1008-1014.

[10] G.G. Chen, J.F. Lee, S.H. Wang, U.P. Chan, P.C. Ip, W.Y. Lau, Apoptosis induced by activation of peroxisome-proliferator activated receptor-gamma is associated with Bcl-2 and NF-kappaB in human colon cancer, Life Sci. 70 (2002) 2631 2646.

[11] D. Panigrahy, S. Singer, L.Q. Shen, C.E. Butterfield, D.A. Freedman, E.J. Chen, et al., PPARgamma ligands inhibit primary tumor growth and metastasis by inhibiting angiogenesis, J. Clin. Invest. 110 (2002) 923-932.

[12] G. Pascual, A.L. Fong, S. Ogawa, A. Gamliel, A.C. Li, V. Perissi, et al., A SUMOylation-dependent pathway mediates transrepression of inflammatory response genes by PPAR-gamma, Nature 437 (2005) 759-763.

[13] L. Sabatino, A. Fucci, M. Pancione, V. Carafa, A. Nebbioso, C. Pistore, et al., UHRF1 coordinates peroxisome proliferator activated receptor gamma (PPARG) epigenetic silencing and mediates colorectal cancer progression, Oncogene 31 (2012) 5061-5072. 
[14] T. Shimada, K. Kojima, K. Yoshiura, H. Hiraishi, A. Terano, Characteristics of the peroxisome proliferator activated receptor gamma (PPARgamma) ligand induced apoptosis in colon cancer cells, Gut 50 (2002) 658-664.

[15] E.A. Thompson, PPARgamma physiology and pathology in gastrointestinal epithelial cells, Mol. Cells 24 (2007) 167-176.

[16] P. Sarraf, E. Mueller, D. Jones, F.J. King, D.J. DeAngelo, J.B. Partridge, et al., Differentiation and reversal of malignant changes in colon cancer through PPARgamma, Nat. Med. 4 (1998) 1046-1052.

[17] I.A. Voutsadakis, Peroxisome proliferator-activated receptor gamma (PPARgamma) and colorectal carcinogenesis, J. Cancer Res. Clin. Oncol. 133 (2007) 917-928.

[18] H.P. Koeffler, Peroxisome proliferator-activated receptor gamma and cancers, Clin. Cancer Res. 9 (2003) 1-9.

[19] M. Lehrke, M.A. Lazar, The many faces of PPARgamma, Cell 123 (2005) $993-$ 999.

[20] J.N. Feige, L. Gelman, L. Michalik, B. Desvergne, W. Wahli, From molecular action to physiological outputs: peroxisome proliferator-activated receptors are nuclear receptors at the crossroads of key cellular functions, Prog. Lipid Res. 45 (2006) 120-159.

[21] V. Perissi, M.G. Rosenfeld, Controlling nuclear receptors: the circular logic of cofactor cycles, Nat. Rev. Mol. Cell Biol. 6 (2005) 542-554.

[22] M. Ricote, C.K. Glass, PPARs and molecular mechanisms of transrepression, Biochim. Biophys. Acta 1771 (2007) 926-935.

[23] L. Michalik, J. Auwerx, J.P. Berger, V.K. Chatterjee, C.K. Glass, F.J. Gonzalez, et al., International Union of Pharmacology. LXI. Peroxisome proliferator-activated receptors, Pharmacol. Rev. 58 (2006) 726-741.

[24] R.K. Semple, V.K. Chatterjee, S. O’Rahilly, PPAR gamma and human metabolic disease, J. Clin. Invest. 116 (2006) 581-589.

[25] A. Grey, Skeletal consequences of thiazolidinedione therapy, Osteoporos. Int. 19 (2008) 129-137.

[26] A. Rubenstrunk, R. Hanf, D.W. Hum, J.C. Fruchart, B. Staels, Safety issues and prospects for future generations of PPAR modulators, Biochim. Biophys. Acta 1771 (2007) 1065-1081.

[27] B.G. Shearer, A.N. Billin, The next generation of PPAR drugs: do we have the tools to find them? Biochim. Biophys. Acta 1771 (2007) 1082-1093.

[28] J.P. Berger, A.E. Petro, K.L. Macnaul, L.J. Kelly, B.B. Zhang, K. Richards, et al., Distinct properties and advantages of a novel peroxisome proliferatoractivated protein [gamma] selective modulator, Mol. Endocrinol. 17 (2003) 662-676.

[29] S.M. Rangwala, M.A. Lazar, The dawn of the SPPARMs? Sci. STKE 2002 (2002). pe9.

[30] J.H. Choi, A.S. Banks, T.M. Kamenecka, S.A. Busby, M.J. Chalmers, N. Kumar et al., Antidiabetic actions of a non-agonist PPARgamma ligand blocking Cdk5mediated phosphorylation, Nature 477 (2011) 477-481.

[31] W. Wang, L. Heideman, C.S. Chung, J.C. Pelling, K.J. Koehler, D.F. Birt, Cell-cycle arrest at G2/M and growth inhibition by apigenin in human colon carcinoma cell lines, Mol. Carcinog. 28 (2000) 102-110.

[32] F.D. Piaz, N. Malafronte, A. Romano, D. Gallotta, M.A. Belisario, G. Bifulco, et al. Structural characterization of tetranortriterpenes from Pseudrocedrela kotschy and Trichilia emetica and study of their activity towards the chaperone Hsp90, Phytochemistry 75 (2012) 78-89.

[33] C.C. Huang, G.S. Couch, E.F. Pettersen, T.E. Ferrin, Chimera: an extensible molecular modeling application constructed using standard components, Pac. Symp. Biocomput. (1996) 1519-1523.

[34] G. Jones, P. Willett, R.C. Glen, A.R. Leach, R. Taylor, Development and validation of a genetic algorithm for flexible docking, J. Mol. Biol. 267 (1997) 727-748.

[35] R. Montanari, F. Saccoccia, E. Scotti, M. Crestani, C. Godio, F. Gilardi, et al. Crystal structure of the peroxisome proliferator-activated receptor gamma (PPARgamma) ligand binding domain complexed with a novel partial agonist: a new region of the hydrophobic pocket could be exploited for drug design, J. Med. Chem. 51 (2008) 7768-7776.

[36] N. Micale, R. Ettari, A. Lavecchia, C. Di Giovanni, K. Scarbaci, V. Troiano, et al., Development of peptidomimetic boronates as proteasome inhibitors, Eur. J Med. Chem. 64 (2013) 23-34.

[37] L. Porcelli, F. Gilardi, A. Laghezza, L. Piemontese, N. Mitro, A. Azzariti, et al., Synthesis, characterization and biological evaluation of ureidofibrate-like derivatives endowed with peroxisome proliferator-activated receptor activity, J. Med. Chem. 55 (2012) 37-54.

[38] M.G. Perrone, P. Vitale, P. Malerba, A. Altomare, R. Rizzi, A. Lavecchia, et al., Diarylheterocycle core ring features effect in selective COX-1 inhibition, ChemMedChem 7 (2012) 629-641.

[39] P. Vitale, M.G. Perrone, P. Malerba, A. Lavecchia, A. Scilimati, Selective COX-1 inhibition as a target of theranostic novel diarylisoxazoles, Eur. J. Med. Chem. 74 (2014) 606-618.
[40] K. Scarbaci, V. Troiano, N. Micale, R. Ettari, L. Tamborini, C. Di Giovanni, et al., Identification of a new series of amides as non-covalent proteasome inhibitors, Eur. J. Med. Chem. 76 (2014) 1-9.

[41] M.A. Cooper, Label-free screening of bio-molecular interactions, Anal. Bioanal. Chem. 377 (2003) 834-842.

[42] T.M. Santosusso, D. Swern, Chemistry of epoxides. XXXI. Acid-catalyzed reactions of epoxides with dimethyl sulfoxide, J. Org. Chem. 40 (1975) 2764-2769.

[43] M.A. Khuddus, D. Swern, Chemistry of epoxides. XXIX. Alkoxysulfonium salts from dimethyl sulfoxide and epoxides. Preparation, characterization, reactions, and mechanistic studies, J. Am. Chem. Soc. 95 (1973) 8393-8402.

[44] R. Parker, N. Isaacs, Mechanisms of epoxide reactions, Chem. Rev. 59 (1959) 737-799.

[45] D. Swern, Reactions of the oxirane group, J. Am. Oil Chem. Soc. 47 (1970) $424-$ 429.

[46] M.L. Verdonk, I. Giangreco, R.J. Hall, O. Korb, P.N. Mortenson, C.W. Murray, Docking performance of fragments and druglike compounds, J. Med. Chem. 54 (2011) 5422-5431.

[47] G. Pochetti, C. Godio, N. Mitro, D. Caruso, A. Galmozzi, S. Scurati, et al., Insights into the mechanism of partial agonism: crystal structures of the peroxisome proliferator-activated receptor gamma ligand-binding domain in the complex with two enantiomeric ligands, J. Biol. Chem. 282 (2007) 17314-17324.

[48] A. Farce, N. Renault, P. Chavatte, Structural insight into PPARgamma ligands binding, Curr. Med. Chem. 16 (2009) 1768-1789.

[49] S.K. Burley, G.A. Petsko, Amino-aromatic interactions in proteins, FEBS Lett. 203 (1986) 139-143.

[50] R.T. Nolte, G.B. Wisely, S. Westin, J.E. Cobb, M.H. Lambert, R. Kurokawa, et al., Ligand binding and co-activator assembly of the peroxisome proliferatoractivated receptor-gamma, Nature 395 (1998) 137-143.

[51] C. Hellal-Levy, J. Fagart, A. Souque, J.M. Wurtz, D. Moras, M.E. Rafestin-Oblin, Crucial role of the H11-H12 loop in stabilizing the active conformation of the human mineralocorticoid receptor, Mol. Endocrinol. 14 (2000) 1210-1221.

[52] G. Pochetti, N. Mitro, A. Lavecchia, F. Gilardi, N. Besker, E. Scotti, et al. Structural insight into peroxisome proliferator-activated receptor gamma binding of two ureidofibrate-like enantiomers by molecular dynamics, cofactor interaction analysis, and site-directed mutagenesis, J. Med. Chem. 53 (2010) 4354-4366.

[53] I.L. Lu, C.F. Huang, Y.H. Peng, Y.T. Lin, H.P. Hsieh, C.T. Chen, et al., Structurebased drug design of a novel family of PPARgamma partial agonists: virtual screening, X-ray crystallography, and in vitro/in vivo biological activities, J. Med. Chem. 49 (2006) 2703-2712.

[54] J.B. Bruning, M.J. Chalmers, S. Prasad, S.A. Busby, T.M. Kamenecka, Y. He, et al., Partial agonists activate PPARgamma using a helix 12 independent mechanism, Structure 15 (2007) 1258-1271.

[55] T. Shiraki, N. Kamiya, S. Shiki, T.S. Kodama, A. Kakizuka, H. Jingami, Alpha, beta-unsaturated ketone is a core moiety of natural ligands for covalent binding to peroxisome proliferator-activated receptor gamma, J. Biol. Chem. 280 (2005) 14145-14153.

[56] N. Heldring, A. Pike, S. Andersson, J. Matthews, G. Cheng, J. Hartman, et al., Estrogen receptors: how do they signal and what are their targets, Physiol. Rev. 87 (2007) 905-931.

[57] M.G. Rosenfeld, V.V. Lunyak, C.K. Glass, Sensors and signals: a coactivator/corepressor/epigenetic code for integrating signal-dependent programs of transcriptional response, Genes Dev. 20 (2006) 1405-1428.

[58] L.S. Higgins, A.M. Depaoli, Selective peroxisome proliferator-activated receptor gamma (PPARgamma) modulation as a strategy for safer therapeutic PPARgamma activation, Am. J. Clin. Nutr. 91 (2010) 267S-272S.

[59] V. Zoete, A. Grosdidier, O. Michielin, Peroxisome proliferator-activated receptor structures: ligand specificity, molecular switch and interactions with regulators, Biochim. Biophys. Acta 1771 (2007) 915-925.

[60] S. Yu, J.K. Reddy, Transcription coactivators for peroxisome proliferatoractivated receptors, Biochim. Biophys. Acta 1771 (2007) 936-951.

[61] T. Fujimura, H. Sakuma, S. Konishi, T. Oe, N. Hosogai, C. Kimura, et al., FK614, a novel peroxisome proliferator-activated receptor gamma modulator, induces differential transactivation through a unique ligand-specific interaction with transcriptional coactivators, J. Pharmacol. Sci. 99 (2005) 342-352.

[62] L. Sabatino, M. Pancione, C. Votino, T. Colangelo, A. Lupo, E. Novellino, et al., Emerging role of the beta-catenin-PPARgamma axis in the pathogenesis of colorectal cancer, World J. Gastroenterol. 20 (2014) 7137-7151.

[63] H.A. Elrod, S.Y. Sun, PPARgamma and apoptosis in cancer, PPAR Res. 2008 (2008) 704165

[64] J.M. Phang, S.P. Donald, J. Pandhare, Y. Liu, The metabolism of proline, a stress substrate, modulates carcinogenic pathways, Amino Acids 35 (2008) 681-690. 